\title{
Guidelines in the management of diabetic nerve pain: clinical utility of pregabalin
}

This article was published in the following Dove Press journal:

Diabetes, Metabolic Syndrome and Obesity:Targets and Therapy

23 February 2013

Number of times this article has been viewed

\author{
Aaron IVinik \\ Carolina M Casellini \\ Strelitz Diabetes Center for \\ Endocrine and Metabolic Disorders, \\ Eastern Virginia Medical School, \\ Norfolk, VA, USA
}

Correspondence: Aaron I Vinik Research and Neuroendocrine Unit, Strelitz Diabetes Center for Endocrine and Metabolic Disorders and Division of Endocrinology and Metabolism, Department of Medicine, Eastern Virginia Medical School, Andrews Hall, 72I Fairfax Avenue, Norfolk, VA 23507, USA

$\mathrm{Tel}+\mathrm{I} 7574465912$

Fax + I 7574465868

Email vinikai@evms.edu
Abstract: Diabetic peripheral neuropathy is a common complication of diabetes. It presents as a variety of syndromes for which there is no universally accepted unique classification. Sensorimotor polyneuropathy is the most common type, affecting about $30 \%$ of diabetic patients in hospital care and $25 \%$ of those in the community. Pain is the reason for $40 \%$ of patient visits in a primary care setting, and about $20 \%$ of these have had pain for greater than 6 months. Chronic pain may be nociceptive, which occurs as a result of disease or damage to tissue with no abnormality in the nervous system. In contrast, neuropathic pain is defined as "pain arising as a direct consequence of a lesion or disease affecting the somatosensory system." Persistent neuropathic pain interferes significantly with quality of life, impairing sleep and recreation; it also significantly impacts emotional well-being, and is associated with depression, anxiety, and noncompliance with treatment. Painful diabetic peripheral neuropathy is a difficult-to-manage clinical problem, and patients with this condition are more apt to seek medical attention than those with other types of diabetic neuropathy. Early recognition of psychological problems is critical to the management of pain, and physicians need to go beyond the management of pain per se if they are to achieve success. This evidence-based review of the assessment of the patient with pain in diabetes addresses the state-of-the-art management of pain, recognizing all the conditions that produce pain in diabetes and the evidence in support of a variety of treatments currently available. A search of the full Medline database for the last 10 years was conducted in August 2012 using the terms painful diabetic peripheral neuropathy, painful diabetic peripheral polyneuropathy, painful diabetic neuropathy and pain in diabetes. In addition, recent reviews addressing this issue were adopted as necessary. In particular, reports from the American Academy of Neurology and the Toronto Consensus Panel on Diabetic Neuropathy were included. Unfortunately, the results of evidence-based studies do not necessarily take into account the presence of comorbidities, the cost of treatment, or the role of third-party payers in decision-making. Thus, this review attempts to give a more balanced view of the management of pain in the diabetic patient with neuropathy and in particular the role of pregabalin.

Keywords: diabetes mellitus, painful neuropathy, pain, treatment, pregabalin

\section{Introduction}

Diabetic peripheral neuropathy is a common complication of diabetes. It presents as a variety of syndromes for which there is no universally accepted unique classification. These are generally subdivided into focal/multifocal neuropathies, including diabetic amyotrophy, and symmetric polyneuropathies, including sensorimotor polyneuropathy (DSPN). The latter is the most common type, affecting about $30 \%$ of diabetic patients in hospital care and $25 \%$ of those in the community. ${ }^{1,2}$ DSPN has been recently defined as a symmetrical, length-dependent sensorimotor polyneuropathy attributable to 
metabolic and microvascular alterations as a result of chronic hyperglycemia exposure (diabetes) and cardiovascular risk covariates. ${ }^{3}$ Its onset is generally insidious, and without treatment its course is chronic and progressive. The loss of small-fiber-mediated sensation results in the loss of thermal and pain perception, whereas large-fiber impairment results in loss of touch and vibration perception. Sensory fiber involvement may also result in "positive" symptoms, such as paresthesias and pain, although up to $50 \%$ of neuropathic patients are asymptomatic. DSPN can be associated with the involvement of the autonomic nervous system, ie, diabetic autonomic neuropathy that rarely causes severe symptoms, ${ }^{4,5}$ but in its cardiovascular form is definitely associated with at least a threefold increased risk for mortality. ${ }^{6-8}$

Pain is the reason for $40 \%$ of patient visits in a primary care setting, and about $20 \%$ of these have had pain for longer than 6 months. ${ }^{9}$ Chronic pain may be nociceptive, which occurs as a result of disease or damage to tissue wherein there is no abnormality in the nervous system. In contrast, experts in the neurology and pain community define neuropathic pain as "pain arising as a direct consequence of a lesion or disease affecting the somatosensory system." ${ }^{10}$ Persistent neuropathic pain interferes significantly with quality of life (QOL), impairing sleep and recreation; it also significantly impacts emotional well-being, and is associated with, if not the cause of, depression, anxiety, loss of sleep, and noncompliance with treatment. ${ }^{11}$ Painful diabetic peripheral neuropathy (PDPN) is a difficult-to-manage clinical problem, and patients with PDPN are more apt to seek medical attention than those with other types of diabetic neuropathy. Two populationbased studies showed that neuropathic pain is associated with a greater psychological burden than nociceptive pain ${ }^{12}$ and is considered to be more severe than other pain types. Early recognition of psychological problems is critical to the management of pain, and physicians need to go beyond the management of pain per se if they are to achieve success. Patients may also complain of decreased physical activity and mobility, increased fatigue, and negative effects on their social lives. Providing significant pain relief markedly improves QOL measures, including sleep and vitality. ${ }^{13,14}$

This evidence-based review on the management of the patient with painful diabetic neuropathy will address stateof-the-art management of pain, recognizing all the conditions that produce pain in diabetes and the evidence in support of a variety of treatments currently available. Unfortunately, the results of evidence-based studies do not necessarily take into account the cost of treatment and the role of the third-party payers in decision-making. The reader should appreciate that there is no concordance between the strength of the evidence and the strength of action of the drug. Nor has the American Academy of Neurology (AAN), on the recent guidelines for the treatment of painful diabetic neuropathy, ${ }^{15}$ considered the comorbidities in their recommendations; thus, this review attempts to give a more balanced view of the management of pain in the diabetic patient and in particular the role of pregabalin.

\section{Pain and its comorbidities}

Neuropathic pain is the consequence of an array of diseases or injuries to the peripheral or central nervous system. It is often chronic, and if inadequately treated, patients often experience anxiety, depression, and catastrophizing behavior, an inability to accept chronic pain, and sleep disturbances. Treatment of neuropathic pain conditions can benefit from further understanding of the impact of pain response on QOL, including anxiety, depression, sleep disturbances, physical functions, and activities of daily living.

Castro and Daltro ${ }^{16}$ studied 400 patients with depression, anxiety, and sleep disturbances. Two-thirds of depressed patients and three-quarters of anxious patients had pain, but the most impressive finding was that $>90 \%$ of sleep-deprived patients had experienced pain. As a corollary, Gore et $\mathrm{al}^{17}$ showed that with increasing pain severity, there was a linear increase in Hospital Anxiety and Depression Scale pain and depression scores. The impact of depression complicated the diabetes management, increased the length of hospital stays, and almost doubled the yearly cost of diabetes management from US\$7000 to $\$ 11,000 .{ }^{18}$ Moreover Gupta et al showed that higher scores for anxiety, depression, and sleep disturbances predicted the development of pain. ${ }^{19}$

Vinik et al examined data from five PDPN, four postherpetic neuralgia (PHN), and one PDPN/PHN doubleblind, placebo-controlled, randomized clinical trials of 8-13 weeks' duration, using pregabalin. The data showed a direct relationship between the reduction in pain and enhanced sleep, as well as improvement in social functioning on the Short Form (36) Health Survey (SF-36) scale. Indeed, the improvement in social functioning depended on pain relief and sleep improvement equally well. In addition, the effects of pregabalin on pain relief were mediated directly and indirectly through its effects on sleep improvement about equally (Class Ia, recommendation A [see Supplementary material] $).{ }^{20}$ This speaks to the need for determining sleep status in the evaluation of pain and choosing an agent capable of enhancing sleep if pain relief is to be achieved. 
Several studies have consistently found that neuropathic pain has a negative impact on global health-related QOL. A systematic review of 52 studies in patients with one out of six different disorders associated with neuropathic pain, including PDPN, established that neuropathic pain impairs physical and emotional functioning, role functioning, including participation in gainful employment, sleep, and to a lesser degree social functioning. In addition, there is also evidence suggesting an association between neuropathic pain and depression, as for other types of pain. ${ }^{11,21}$ The impact of pain on QOL in PDPN has recently been shown in 1111 patients: physical and mental QOL were significantly more impaired in patients with PDPN vs both diabetic patients without neuropathy and those with non-PDPN..$^{22}$ Also the nature and duration of the pain may be important. Daousi et al reported significantly poorer QOL (measured by Pain Disability Score) in patients with chronic PDPN (duration of 1 year or more) vs diabetic patients without chronic PDPN. ${ }^{23}$

Targeted studies in diabetic patients have shown that chronic and severe pain significantly interferes with overall diabetes self-management $(P=0.002$ and $P=0.0003$, respectively), and neuropathic pain significantly interferes with the quality of sleep measured by the Medical Outcomes Study Sleep Scale. The results of these studies were significantly worse in a sample of 255 PDPN patients than in the general population $(\mathrm{n}=1011)$, a chronic-disease sample $(n=3445)$, and postherpetic neuralgia patients $(n=89){ }^{24,25}$

\section{Epidemiology of neuropathic pain}

Neuropathic pain is not uncommon. A population-based survey of 6000 patients treated in family practice in the UK reported a $6 \%$ prevalence of pain, predominantly of neuropathic origin. ${ }^{26}$ Similarly, a large population-based study in France showed that $6.9 \%$ of the population had neuropathic pain. ${ }^{12}$ Interestingly, in a Dutch population survey of $>362,000$ persons, younger people with pain tended to be mostly women, but with advancing age the sex differences disappeared. Perhaps a little-recognized fact is that mononeuritis and entrapments were three times as common as diabetic peripheral neuropathy (DPN), and fully one-third of the diabetic population has some form of entrapment, ${ }^{27}$ which when recognized is readily amenable to intervention. ${ }^{28}$ Even more salutary is the mounting evidence that even with impaired glucose tolerance (IGT), patients may experience pain. ${ }^{22,29,30}$ In the general population (region of Augsburg, Southern Germany), the prevalence of painful peripheral neuropathy was $13.3 \%$ in the diabetic subjects, $8.7 \%$ in those with IGT, $4.2 \%$ in those with impaired fasting glucose, and $1.2 \%$ in those with normal glucose tolerance. ${ }^{31}$ Among survivors of myocardial infarction (MI) from the Augsburg MI Registry, the prevalence of neuropathic pain was $21 \%$ in patients with diabetes, $14.8 \%$ in those with IGT, $5.7 \%$ in those with impaired fasting glucose, and $3.7 \%$ in those with normal glucose tolerance. ${ }^{30}$ Thus, subjects with macrovascular disease appear to be prone to neuropathic pain. The most important risk factors of DSPN and neuropathic pain in these surveys were age, obesity, and low physical activity, while the predominant comorbidity was peripheral arterial disease, highlighting the paramount role of cardiovascular risk factors and diseases in prevalent DSPN. In conclusion, patients presenting with painful neuropathy frequently have impaired fasting glucose or impaired glucose tolerance, and about $50 \%$ of the time are overweight and have autonomic dysfunction. ${ }^{29}$ Even in the absence of elevated fasting blood glucose $(<100 \mathrm{mg} / \mathrm{dL})$, pain may be the presenting feature of metabolic syndrome and cosegregates with elevated triglycerides and low high-density lipoprotein cholesterol. ${ }^{32}$ Indeed, a risk factor for neuropathic pain in diabetic and nondiabetic populations is an impairment of peripheral vascular function. ${ }^{30,33}$ A recent observational study of a large cohort of diabetic patients in northwest England $(n=15,692)$ evaluated the prevalence of painful diabetic neuropathy. PDPN was assessed using the Neuropathy Symptom Score and the Neuropathy Disability Score. The researchers concluded that one-third of all community-based diabetic patients have painful neuropathy symptoms, regardless of their neuropathic deficit. PDPN was more prevalent in patients with type 2 diabetes, women, and people of South Asian origin. ${ }^{34}$ This study shows significant morbidity due to painful neuropathy and identifies key groups who warrant screening for PDPN.

\section{Pain characteristics}

Pain associated with a peripheral nerve injury has several distinct clinical characteristics. Neuropathic pain derived from small nerve fibers is often burning, lancinating, or shooting in quality, with unusual, tingling, or crawling sensation referred to as formication. Some describe bees stinging through the socks while others talk of walking on hot coals. The pain, worse at night, keeps the patient awake and is associated with sleep deprivation. ${ }^{13}$ Patients volunteer allodynia (pain due to a stimulus that does not normally cause pain eg, stroking) or pain from normal stimuli, such as the touch of bedclothes, and may have hyperesthesias (increased sensitivity to touch) or hyperalgesia (increased sensitivity to painful stimuli) and even altered sensation to cold or heat. These may be paradoxical with differences in 
sensation to one or other modality of stimulation. Unlike animal models of DPN, the pain is spontaneous and does not need provocation. It has a glove-and-stocking distribution. Small-fiber neuropathies usually present with pain in the feet or hands, do not have abnormalities in sensation, lack weakness or loss of reflexes, and are electrophysiologically silent, thus often leading to the erroneous diagnosis of hysteria or conversion reactions. Pain usually occurs at rest and improves with ambulation vs osteoarthritic pain, which is worsened with ambulation and decreased with rest. Pain may persist over several years, ${ }^{35}$ causing considerable disability and impaired QOL in some patients, ${ }^{36}$ whereas it remits partially or completely in others ${ }^{37,38}$ despite further deterioration in small-fiber function. ${ }^{38}$ Pain exacerbation or even acute onset of pain tends to be associated with sudden metabolic changes, insulin neuritis, short duration of pain or diabetes, or preceding weight loss, and has less severe or no sensory loss, and normal strength and reflexes. ${ }^{37,38}$

Large-fiber neuropathy presents with characteristic weakness, ataxia, loss of reflexes, and impaired nerve conduction. Pain is deep-seated and gnawing in quality, "like a toothache" in the foot, or "a dog gnawing at the bones of the feet," or the "feet feel as if they are encased in concrete." DPN tends to interfere with balance and proprioception, resulting in falls, especially in elderly patients.

In contrast, the nociceptive pain of inflammatory arthritis does not have these qualities. It is localized to the joints, starts with morning stiffness, and improves as the day wears on. ${ }^{39}$ Fasciitis pain is localized to the fascia, entrapment produces pain in a dermatome, and claudication is made worse by walking.

\section{The diagnostic workup}

Because of its complexity, the presentation of pain poses a diagnostic dilemma for the clinician who needs to distinguish between neuropathic pain arising as a direct consequence of a lesion or disease of the somatosensory system, and nociceptive pain that is due to trauma, inflammation, or injury. It is imperative to try to establish the nature of any predisposing factor, including the pathogenesis of the pain, if one is to be successful in its management. Management of neuropathic pain requires a sound relationship between patient and physician, with an emphasis on a positive outlook and encouragement that there is a solution, using patience and targeted pain-centered strategies that deal with the underlying disorder rather than the usual band-aid prescription of drugs approved for general pain, which do not address the disease process. The inciting injury may be focal or diffuse, and may involve single or, more likely, multiple mechanisms such as metabolic disturbances encompassing hyperglycemia, dyslipidemia, glucose fluctuations, or intensification of therapy with insulin. On the other hand, the injury might embrace autoimmune mechanisms, neurovascular insufficiency, deficient neurotrophism, oxidative and nitrosative stress, and inflammation. ${ }^{1}$ Because pain syndromes in diabetes may be focal or diffuse, proximal or distal, acute or chronic, each has its own pathogenesis, and the treatment must be tailored to the underlying disorder if the outcome is to be successful. The presence of diabetes must be established if this has not already been done. An A1c or random glucose test may suffice, but in rare instances a full $75 \mathrm{~g}$ glucose tolerance test may need to be done. ${ }^{40}$

\section{Diagnosis of neuropathic pain}

The diagnosis of neuropathic pain - as opposed to pain from causes other than neuropathy - is first and foremost made by careful history-taking. Patients should be queried at the time of an office visit as to whether they are experiencing tingling, burning, or pain at rest in their feet. A positive response warrants further investigation and screening for PDPN. Pain in the first three fingers is carpal tunnel syndrome, pain in the pinky is ulnar entrapment, pain on the lateral side of the shin is peroneal entrapment, pain on the medial side of the foot is medial plantar entrapment, and pain in the space between the first and second metatarsal heads is a Morton's neuroma. Somatosensory, motor, and autonomic bedside evaluation can be done and is complemented by use of one of the pain-screening tools (Douleur Neuropathique 4 questions, painDETECT, etc). ${ }^{41}$ The physician should ensure that all the features of pain, such as distribution, quality, severity, timing, associated symptoms, and exacerbating and relieving factors (if any), are recorded. In particular, the presence of numbness, burning, tingling, lightning pain, stabbing, and prickling should be recorded, as is done in the Norfolk QOL tool (Class Ia, recommendation A [ $\underline{\text { see }}$ Supplementary material] $),{ }^{13}$ the Neuropathy Total Symptom Score-6 Questionnaire (NTSS-6), ${ }^{42}$ and the painDETECT Questionnaire. ${ }^{41}$ Secondly, pain intensity and quality should be assessed, using Pain Intensity Scales (visual analog scale or numerical rating scale) (Class Ia, recommendation A [see Supplementary material] $)^{43}$ and pain questionnaires (Brief Pain Inventory [BPI], Neuropathic Pain Symptom Inventory). A number of tools and questionnaires have been developed to quantify the pain impact on sleep, on mood, and on QOL, mainly to be used in clinical trials. In clinical practice, the BPI Interference Scale, the Profile of Moods 
Scale, or the Hospital Scale for Anxiety and Depression can provide a simple measure of pain impact on QOL. Responses to treatment by self-reporting using a diary can record the course of painful symptoms and their impact on daily life (Class Ia, recommendation A [see Supplementary material] $).{ }^{44}$ These are also most useful for outcomes measures in clinical trials on drugs used for pain relief. Validated scoring systems for symptoms and signs are available in the form of questionnaires or checklists, such as the Neuropathy Symptom Score ${ }^{45}$ and Michigan Neuropathy Screening Instrument Questionnaire ${ }^{46}$ for Symptoms, and the Michigan Neuropathy Screening Instrument ${ }^{46}$ and Neuropathy Disability Score ${ }^{45}$ for signs (Class Ia, recommendation A [see Supplementary material]).

\section{Definition of neuropathic pain}

A definition of peripheral neuropathic pain in diabetes, adapted from a definition proposed by the International Association for the Study of Pain, ${ }^{10}$ is "pain arising as a direct consequence of abnormalities in the peripheral somatosensory system in people with diabetes." 3 A grading system for the degree of certainty of the diagnosis of neuropathic pain has been proposed. It is based on four simple criteria, namely:

1. whether the pain has a distinct neuroanatomical distribution,

2. whether the history of the patient suggests the presence or absence of a lesion or disease of the peripheral or central somatosensory system,

3. whether either of these findings is supported by at least one confirmatory test, and

4. whether there is an abnormality of nerve conduction. ${ }^{10}$

Degree of certainty is defined according to the number of criteria met: 1-4 (definite neuropathic pain); 1 and 2 plus 3 or 4 (probable neuropathic pain); or only 1 and 2 (possible neuropathic pain). ${ }^{10}$ There is no consensus on their diagnostic validity, since neuropathic pain is a composite of pain and other sensory symptoms associated with nerve injury. For example, sensory deficits, abnormal spontaneous or induced sensations such as paresthesias (eg, tingling), spontaneous attacks of electric shock-like sensations, and allodynia preclude a simple definition (see below).

\section{Distinction between nociceptive and nonnociceptive pain}

A number of tools have been developed to differentiate nonnociceptive stimuli (allodynia), increased pain sensitivity to stimuli (hyperalgesia), ${ }^{47}$ and summation, which is progressive worsening of pain caused by repeated mild noxious stimuli (Class IIb, recommendation B [see Supplementary material]) ${ }^{41}$ A number of self-administered questionnaires have been developed, validated, translated, and subjected to cross-cultural adaptation both to diagnose and distinguish neuropathic as opposed to nonneuropathic pain (Leeds Assessment of Neuropathic Symptoms and Signs Pain Scale, Douleur Neuropathique 4 questions, Neuropathic Pain Questionnaire, painDETECT scale, and ID-Pain Questionnaire). ${ }^{41,48-53}$ Others assess pain quality and intensity (assessment questionnaires such as the short-form McGill Pain Questionnaire, the BPI, and the Neuropathic Pain Symptom Inventory) ${ }^{48,54,55}$ (Class III, recommendation B [see Supplementary material]).

According to the Initiative on Methods, Measurement, and Pain Assessment in Clinical Trials, the following pain characteristics should be evaluated to assess the efficacy and effectiveness of chronic pain treatment:

1. pain intensity measured on a $0-10$ numerical rating scale,

2. physical functioning assessed by the Multidimensional Pain Inventory and BPI Interferences Scale,

3. emotional functioning, assessed by the Beck Depression Inventory and profile of mood states, and

4. patient rating of overall improvement, assessed by the Patient Global Impression of Change Scale ${ }^{56}$ (Class III, recommendation B [see Supplementary material]).

\section{Laboratory tests to evaluate neuropathic pain}

Since neuropathic pain is subjective, there are no tests that can objectively quantify this in humans. Tests of pain in animal studies are really measures of reaction time to heat or other stimuli, which is one of the reasons for failure of translation of animal studies to man. Thus, laboratory tests do not reflect spontaneous pain but rather the function of the nociceptive system, and ultimately, with quantitative sensory testing (QST), the evoked positive sensory phenomena associated with neuropathic pain, ie, hyperalgesia and allodynia. This means that the results of laboratory tests become useful only in the context of a comprehensive clinical examination.

Late laser-evoked potentials (A $\delta$ ) are the easiest and most reliable neurophysiological tools for assessing nociceptive A $\delta$-fiber pathway function, useful in both peripheral and central neuropathic pain, with the limitation of very low availability (Class III, recommendation B [see Supplementary material]).$^{57}$ The morphological study of cutaneous nerve fibers using skin biopsy and intraepidermal nerve fiber (IENF) 
density assessment are regarded as reproducible markers of small-fiber sensory pathology. In particular, distal leg-skin biopsy with quantification of IENF density is a reliable and efficient technique to assess the diagnosis of small-fiber neuropathy (European Federation of Neurological Societies Class Ia, recommendation A [see Supplementary material] $),{ }^{58}$ but is still not widely available. Functional neuroimaging techniques, such as positron emission tomography for the central nervous system and functional magnetic resonance imaging for both central and peripheral nervous systems (magnetic resonance neurography), have been used mainly for research purposes to evaluate the central mechanisms of pain in chronic pain conditions or to visualize intraneural and extraneural lesions of peripheral nerves (Class IV, recommendation C [see Supplementary material] $).{ }^{59}$

Contact heat-evoked potential stimulation (CHEPS) was introduced to study nociceptive pathways by using a contact thermode that rapidly increases skin temperature. The CHEPS device delivers rapid heat pulses to selectively stimulate $\mathrm{A} \delta$ and $\mathrm{C}$ fibers while simultaneously recording cerebral evoked potentials. Several groups have established CHEPS as a clinically feasible approach to examine the physiology of thermonociceptive nerves. CHEPS is a noninvasive technique that can objectively evaluate small-fiber dysfunction. It has been shown that patients with sensory neuropathy of different etiologies have lower CHEPS amplitudes, which correlates with IENF densities. ${ }^{60-62}$ A number of studies have specifically investigated the utility of CHEPS in the evaluation of DPN, with satisfactory results. ${ }^{63,64}$ Chao et al evaluated 32 type 2 diabetic patients with painful neuropathy. CHEPS amplitudes were reduced in diabetic patients compared with age- and sex-matched control subjects $(14.8 \pm 15.6$ vs $33.7 \pm 10.1 \mu \mathrm{V}, P<0.001)$. Abnormal CHEPS patterns (reduced amplitude or prolonged latency) were noted in $81.3 \%$ of these patients. The CHEPS amplitude was the most significant parameter correlated with IENF density $(P=0.003)$ and pain perception to contact-heat stimuli $(P=0.019)$ on multiple linear regression models. ${ }^{63}$ Our group evaluated 31 healthy controls and 30 patients with type 2 diabetes and DPN using neurologic examination, nerve-conduction studies, autonomic function tests, QST, and CHEPS. CHEPS amplitudes were significantly reduced in the DPN group at the lower back $(44.93 \pm 6.5$ vs $23.87 \pm 3.36 \mu \mathrm{V}, P<0.01)$, lower leg $(15.87 \pm 1.99$ vs $11.68 \pm 1.21 \mu \mathrm{V}, P<0.05)$, and dorsal forearm $(29.89 \pm 8.86$ vs $14.96 \pm 1.61 \mu \mathrm{V}, P<0.05)$. Pooled data from both groups showed that amplitudes and latencies at different sites significantly correlated with clinical neurologic scores, nerve-conduction studies, QST, and autonomic function. We calculated the efficiency of CHEPS to reflect total neuropathy scores. Receiver operating characteristic curve analysis, used to evaluate the performance of CHEPS in detecting nerve dysfunction, was most significant for intrapeak amplitudes (IA) at the lower back (area under the curve $0.778 \pm$ standard error $0.06,95 \%$ confidence interval [CI] 0.654-0.875; $P<0.0001$ ) (Parson, unpublished data, 2012). These results suggest that CHEPS is a novel, noninvasive technique able to detect impairment of small nerve-fiber function from skin to cerebral cortex. It provides an objective measure of $\mathrm{C}$ and $\mathrm{A} \delta$ thermonociceptive nerve dysfunction in patients with diabetes, and it has great potential for application to interventional studies.

Evaluation of pain intensity is essential for monitoring response to therapy. There are a number of symptombased screening tools, such as the NTSS-6, BPI, QOL-DN, SF-36, visual analog scale for pain intensity, Neuro-QOL, and Norfolk neuropathy symptoms score (Class Ia, recommendation A [see Supplementary material] $).{ }^{65}$ With the visual analog scale, the patient marks the intensity of their pain on a scale from 0 to 10 , allowing an assessment of the response to intervention. Simultaneously, the patient should complete a QOL tool such as the Norfolk QOL-DN, which needs to include comorbidities such as anxiety, depression, and sleep interference (Class Ia, recommendation A [ $\underline{\text { see }}$ Supplementary material] $).{ }^{13}$

\section{Pharmacological therapeutic modalities for diabetic neuropathic pain}

Painful symptoms in DSPN may constitute a considerable management problem. The efficacy of a single therapeutic agent is not the rule, and simple analgesics are usually inadequate to control the pain. There is agreement that patients should be offered available therapies in a stepwise fashion (Class Ia, recommendation A [see Supplementary material] $).{ }^{66-69}$ Effective pain treatment considers a favorable balance between pain relief and side effects without implying a maximum effect. The following general considerations in the pharmacotherapy of neuropathic pain require attention:

- The appropriate and effective drug has to be tried and identified in each patient by carefully titrating the dose based on efficacy and side effects.

- Lack of efficacy should be judged only after 2-4 weeks of treatment using an adequate dose.

- Because the evidence from clinical trials suggests only a maximum response of $\approx 50 \%$ for any monotherapy, analgesic combinations may be useful. 
Table I Odds ratios for efficacy and withdrawal, numbers needed to treat (NNT) and numbers needed to harm (NNH)

\begin{tabular}{|c|c|c|c|c|}
\hline Drug class & Odds ratio - efficacy & Odds ratio - withdrawal (2ry to AE) & NNT & NNH \\
\hline Tricyclics & $22.2(5.8-84.7)$ & $2.3(0.6-9.7)$ & $1.5-3.5$ & $2.7-17.0$ \\
\hline Duloxetine & $2.6(1.6-4.8)$ & $2.4(1.1-5.4)$ & $5.7-5.8$ & 15.0 \\
\hline Traditional anticonvulsants & $5.3(1.8-16.0)$ & $1.5(0.3-7.0)$ & $2.1-3.2$ & $2.7-3.0$ \\
\hline New generation anticonvulsants & $3.3(2.3-4.7)$ & $3.0(1.75-5.1)$ & $2.9-4.3$ & 26.1 \\
\hline Opioids & $4.3(2.3-7.8)$ & $4.1(1.2-14.2)$ & $2.6-3.9$ & 9.0 \\
\hline
\end{tabular}

Note: Copyright (C) 2010, The Endocrine Society. Reproduced with permission from Vinik A. The approach to the management of the patient with neuropathic pain. J Clin Endocrinol Metab. 2010;95:4802-48।1.70

Abbreviation: 2ry to $A E$, secondary to adverse events.

- Potential drug interactions have to be considered, given the frequent use of polypharmacy in diabetic patients.

The relative benefit of an active treatment over a control in clinical trials is usually expressed as the relative risk, the relative risk reduction, or the odds ratio. However, to estimate the extent of a therapeutic effect (ie, pain relief) that can be translated into clinical practice, it is useful to apply a simple measure that serves the physician to select the appropriate treatment for the individual patient. Such a practical measure is the number needed to treat (NNT), ie, the number of patients that need to be treated with a particular therapy to observe a clinically relevant effect or adverse event in one patient. The odds ratio, NNT, and number needed to harm for the individual agents used in the treatment of painful diabetic neuropathy are given in Table $1^{70}$ and Figure 1. Usually, drugs with NNTs exceeding six for $\geq 50 \%$ pain relief are regarded as showing limited efficacy. However, some authors have cautioned that summary NNT estimates may have limited clinical relevance, due to problems of heterogeneity. ${ }^{71}$

A summary of the AAN recommendations,${ }^{15}$ The Toronto Consensus Panel on Diabetic Neuropathy guidelines, ${ }^{72}$ and treatment options for symptomatic PDPN are shown in Tables 2-5. ${ }^{15,70,72}$

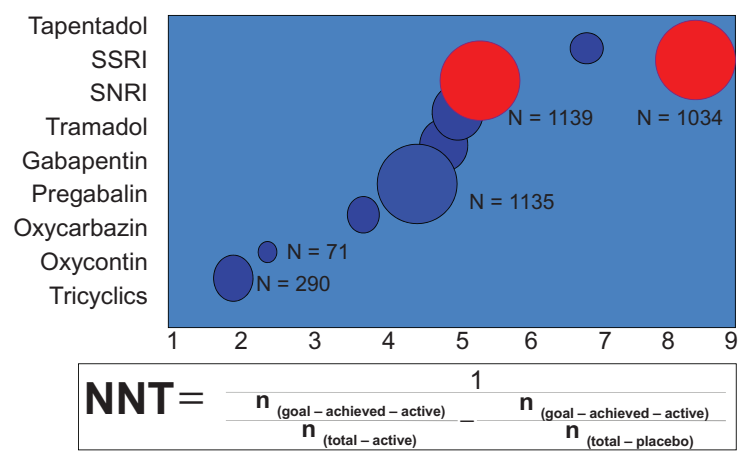

Figure I Efficacy analysis of drugs used for painful diabetic neuropathy. Note: Copyright () 2012, MDTEXT.COM, INC. Reproduced with permission from Endotext.org [homepage on the internet]. Darmouth: Chapter 3I - Diabetic Neuropathies; 2012 version [updatedSeptember 26,20I2]. Availablefrom: http://www. endotext.org/diabetes/diabetes31/diabetesframe3I.htm. Accessed December 12, $2012 .{ }^{154}$
The growing knowledge about the neural and pharmacologic basis of neuropathic pain is likely to have important treatment implications, including development and refinement of a symptom-/mechanism-based approach to neuropathic pain and implementation of novel treatment strategies using the newer antiepileptic agents, which may address the underlying neurophysiologic aberrations in neuropathic pain, allowing the clinician to increase the likelihood of effective management. The neuropharmacology of pain is also becoming better understood. For example, recent data suggest that gamma-aminobutyric acid (GABA), voltage-gated sodium channels, and glutamate receptors may be involved in the pathophysiology of neuropathic pain. Many of the newer agents have significant effects on these neurophysiologic mechanisms. Hyperglycemia may be a factor in lowering the pain threshold. Pain is often worse with wide glycemic excursions. Paradoxically, acute onset of pain may appear soon after initiation of therapy with insulin or oral agents. ${ }^{73}$ In contrast, it has been reported that a striking amelioration of symptoms can occur with continuous subcutaneous insulin administration, which may reduce the amplitude of excursions of blood glucose. ${ }^{73}$ This dichotomy is not well explained. There is a sequence in diabetic neuropathy beginning when $\mathrm{A} \delta$ and $\mathrm{C}$ nerve-fiber function is intact and there is no pain. With damage to $\mathrm{C}$ fibers, there is sympathetic sensitization, and peripheral autonomic symptoms are interpreted as painful. Topical application of clonidine causes antinociception by blocking emerging pain signals at the peripheral terminals via alpha-2 adrenoreceptors,${ }^{74}$ in contrast with the central actions of clonidine on blood pressure control. With the death of $\mathrm{C}$ fibers, there is nociceptor sensitization. A fibers conduct all varieties of peripheral stimuli, such as touch, and these are interpreted as painful, eg, allodynia. With time, there is reorganization at the cord level, and the patient experiences cold hyperalgesia and ultimately, even with the death of all fibers, pain is registered in the cerebral cortex, whereupon the syndrome becomes chronic without the need for peripheral stimulation. Disappearance of pain 
Table 2 Summary of American Academy of Neurology recommendations

\begin{tabular}{|c|c|c|}
\hline Evidence level & Recommended & Not recommended \\
\hline Level A & Pregabalin $300-600$ mg/day & Oxcarbazepine \\
\hline \multirow[t]{12}{*}{ Level B } & Gabapentin 900-3600 mg/day & Lamotrigine \\
\hline & Duloxetine $60-120 \mathrm{mg} /$ day & Lacosamide \\
\hline & Amitriptyline $25-100$ mg/day & Clonidine \\
\hline & Venlafaxine $75-225 \mathrm{mg} /$ day & Pentoxifylline \\
\hline & Sodium valproate $500-1200 \mathrm{mg} /$ day & Mexiletine \\
\hline & Dextromethorphan 400 mg/day & Magnetic field treatment \\
\hline & Morphine titrated to $120 \mathrm{mg} /$ day & Low-intensity laser therapy \\
\hline & Tramadol $210 \mathrm{mg} /$ day & Reiki therapy \\
\hline & Oxycodone 37 mg/day (max 120 mg/day) & \\
\hline & Capsaicin, 0.075\% QID & \\
\hline & Isosorbide dinitrate spray & \\
\hline & TENS $\times 3-4$ & \\
\hline
\end{tabular}

Note: Copyright (c) 20I I, Wolters Kluwer Health. Reprinted with permission from Bril V, England J, Franklin GM, et al. Evidence-based guideline: treatment of painful diabetic neuropathy: report of the American Academy of Neurology, the American Association of Neuromuscular and Electrodiagnostic Medicine, and the American Academy of Physical Medicine and Rehabilitation. Neurology. 2011;76:1758-1765.15

Abbreviations: QID, four times a day; TENS, transcutaneous electrical nerve stimulation.

may not necessarily reflect nerve recovery but rather nerve death. When patients volunteer the loss of pain, progression of the neuropathy must be excluded by careful examination.

\section{$\alpha$-lipoic acid}

According to a meta-analysis comprising 1258 patients, infusions of $\alpha$-lipoic acid (600 mg intravenously/day) ameliorated neuropathic symptoms and deficits after 3 weeks. ${ }^{75}$ Moreover, the Symptomatic Diabetic Neuropathy 2 trial suggests that treatment for 5 weeks using $600 \mathrm{mg}$ of $\alpha$-lipoic acid per day reduces the chief symptoms of DSPN, including pain, paresthesias, and numbness, to a clinically meaningful degree. ${ }^{76}$ In a multicenter, randomized, double-masked, parallel-group clinical trial (Neurological Assessment of Thioctic Acid in Diabetic Neuropathy 1) 460 diabetic patients with DSPN were randomly assigned to oral treatment with $\alpha$-lipoic acid $600 \mathrm{mg}$

Table 3 Treatment options for symptomatic diabetic polyneuropathy pain dosing and side effects

\begin{tabular}{|c|c|c|c|}
\hline Drug class & Drug & Dose (mg) & Side effects \\
\hline \multirow[t]{4}{*}{ Tricyclics } & Amitryptyline & 50-I50 QHS & $\begin{array}{l}\text { Somnolence, dizziness, dry mouth, } \\
\text { tachycardia }\end{array}$ \\
\hline & Nortriptyline & 50-I50 QHS & $\begin{array}{l}\text { Constipation, urinary retention, } \\
\text { blurred vision }\end{array}$ \\
\hline & Imipramine & $25-150$ QHS & Confusion \\
\hline & Desipramine & $25-150$ QHS & \\
\hline \multirow[t]{2}{*}{ SSRIs } & Paroxetine & 40 QD & $\begin{array}{l}\text { Somnolence, dizziness, } \\
\text { sweating, nausea, anorexia }\end{array}$ \\
\hline & Citalopram & $40 \mathrm{QD}$ & Diarrhea, impotence, tremor \\
\hline SNRIs & Duloxetine & $60 \mathrm{QD}$ & $\begin{array}{l}\text { Nausea, somnolence, dizziness, } \\
\text { anorexia }\end{array}$ \\
\hline \multirow[t]{4}{*}{ Anticonvulsants } & Gabapentin & $300-1200$ TID & $\begin{array}{l}\text { Somnolence, dizziness, } \\
\text { Confusion, ataxia }\end{array}$ \\
\hline & Pregabalin & $50-150$ TID & $\begin{array}{l}\text { Somnolence, confusion, edema, } \\
\text { weight gain }\end{array}$ \\
\hline & $\begin{array}{l}\text { Carbamazepine/ } \\
\text { oxcarbazepine }\end{array}$ & Up to 200 QID & $\begin{array}{l}\text { Dizziness, somnolence, } \\
\text { nausea, leukopenia }\end{array}$ \\
\hline & Topiramate & Up to 400 QD & $\begin{array}{l}\text { Somnolence, dizziness, ataxia, } \\
\text { tremor }\end{array}$ \\
\hline \multirow[t]{2}{*}{ Opioids } & Tramadol & $50-100 \mathrm{BID}$ & Nausea, constipation, somnolence \\
\hline & Oxycodone CR & I0-30 BID & Somnolence, nausea, constipation \\
\hline \multirow[t]{2}{*}{ Topical } & Capsaicin & $0.075 \%$ QID & Local irritation \\
\hline & Lidocaine & $0.04 \%$ QD & Local irritation \\
\hline Injection & Botulinum toxin & & None \\
\hline
\end{tabular}

Note: Copyright (C) 2010, The Endocrine Society. Reproduced with permission from Vinik A. The approach to the management of the patient with neuropathic pain. J Clin Endocrinol Metab. 2010;95:4802-48II. ${ }^{70}$

Abbreviations: QHS, at bedtime; QD, once a day; QID, four times a day; TID, three times a day; BID, twice a day; SSRIs, selective serotonin reuptake inhibitors; SNRIs, serotonin-norepinephrine reuptake inhibitors. 
Table 4 Treatment algorithm for painful diabetic peripheral neuropathy (Toronto Consensus Panel on Diabetic Neuropathy)

\begin{tabular}{|c|c|c|c|}
\hline \multicolumn{4}{|c|}{ Painful diabetic neuropathy } \\
\hline \multirow[t]{2}{*}{ First line } & $\alpha 2-\delta$ agonist & SNRI & TCA \\
\hline & (pregabalin or gabapentin) & (duloxetine) & \\
\hline \multicolumn{4}{|c|}{ If pain control is inadequate and considering contraindications } \\
\hline Second line & TCA or SNRI & $\begin{array}{l}\text { TCA or } \alpha 2-\delta \text { agonist } \\
\text { (pregabalin or gabapentin) }\end{array}$ & $\begin{array}{l}\text { SNRI or } \alpha 2-\delta \text { agonist } \\
\text { (pregabalin or gabapentin) }\end{array}$ \\
\hline \multicolumn{4}{|c|}{ If pain control is still inadequate } \\
\hline Third line & \multicolumn{3}{|c|}{ Add opioid agonist as combination therapy } \\
\hline
\end{tabular}

$(n=233)$ or placebo $(n=227)$. After 4 years of treatment, neuropathy impairment score (NIS), but not nerve conduction velocity (NCV), was improved, and the drug was well tolerated throughout the trial. ${ }^{77} \mathrm{~A}$ response analysis of clinically meaningful improvement and progression in the NIS and NIS of the lower limbs (NIS-LL) by at least 2 points showed that the rates of clinical responders were significantly higher and the rates of clinical progressors were lower with $\alpha$-lipoic acid vs placebo for NIS $(P=0.013)$ and NIS-LL $(P=0.025)$, respectively. Clinical and postmarketing surveillance studies have revealed a highly favorable safety profile (Class Ia, recommendation A [see Supplementary material] $)^{78,79}$

\section{Adrenergic blockers}

Initially, when there is ongoing damage to the nerves, the patient experiences pain of the burning, lancinating, dysesthetic type often accompanied by hyperalgesia and allodynia. Because the peripheral sympathetic nerve fibers are also small unmyelinated $\mathrm{C}$ fibers, sympathetic blocking agents (clonidine) may improve the pain.

\section{Topical capsaicin}

$C$ fibers utilize the neuropeptide substance $P$ as their neurotransmitter, and depletion of axonal substance P (through the use of capsaicin) will often lead to amelioration of the pain. Prolonged

Table 5 Tailoring treatment to the patient (Toronto Consensus Panel on Diabetic Neuropathy)

\begin{tabular}{ll}
\hline Comorbidities & Contraindications \\
\hline Glaucoma & TCAs \\
Orthostatic hypotension & TCAs \\
Cardiovascular disease & TCAs \\
Hepatic disease & Duloxetine \\
Edema & Pregabalin, gabapentin \\
Unsteadiness and falls & TCAs \\
Weight gain & TCAs, pregabalin, gabapentin \\
Other factors: cost & Duloxetine, pregabalin \\
\hline
\end{tabular}

Note: Copyright (C) 20II, John Wiley and Sons. Adapted with permission from Tesfaye S, Vileikyte L, Rayman G, et al. Painful diabetic peripheral neuropathy: consensus recommendations on diagnosis, assessment and management. Diabetes Metab Res Rev. 201 I;27:629-638. ${ }^{72}$

Abbreviation: TCAs, tricyclic antidepressants. application of capsaicin depletes stores of substance P, and possibly other neurotransmitters, from sensory nerve endings. This reduces or abolishes the transmission of painful stimuli from the peripheral nerve fibers to the higher centers. ${ }^{80}$ Recent analysis of randomized and controlled studies revealed that either repeated application of low doses of capsaicin or single application of high doses affords pain relief. ${ }^{81}$ Capsaicin (trans-8-methyl- $N$ vanillyl-6-nonenamide) is an alkaloid and the most pungent ingredient in the red pepper. It depletes tissues of substance $\mathrm{P}$ and reduces neurogenic plasma extravasation, the flare response, and chemically induced pain. Substance $P$ is present in afferent neurons innervating skin, mainly in polymodal nociceptors, and is considered the primary neurotransmitter of painful stimuli from the peripheral to the central nervous system. Several studies have demonstrated significant pain reduction and improvement in QOL in diabetic patients with painful neuropathy after 8 weeks of treatment with capsaicin cream $0.075 \%{ }^{82} \mathrm{~A}$ criticism has been that a double-blind design is not feasible for topical capsaicin, due to the transient local hyperalgesia (usually mild burning sensation in $>50 \%$ of cases) it may produce as a typical adverse event. Treatment should be restricted to a maximum of 8 weeks, as during this period no adverse effect on sensory function (due to the mechanism of action) was noted in diabetic patients. The $8 \%$ capsaicin patch (Qutenza) which is effective in postherpetic neuralgia $^{83}$ is contraindicated in painful diabetic neuropathy due to desensitization of nociceptive sensory nerve endings, which may theoretically increase the risk of diabetic foot ulcers (Class $\mathrm{IIb}$, recommendation B [see Supplementary material]).

\section{Lidocaine}

A multicenter randomized, open label, parallel-group study with a drug washout phase of up to 2 weeks and a comparative phase of 4-week treatment periods of 5\% lidocaine $(n=99)$ vs pregabalin $(n=94)$ showed that lidocaine was as effective as pregabalin in reducing pain and was free of side effects. ${ }^{84}$ This form of therapy may be of most use in self-limited forms of neuropathy. If successful, therapy can be continued with oral mexiletine. This class of compounds targets the pain caused by hyperexcitability of superficial, free nerve endings. ${ }^{85}$ 
The AAN recommendations are: ${ }^{15}$

- Capsaicin and isosorbide dinitrate spray should be considered for the treatment of PDPN (Class Ib, recommendation A [see Supplementary material]).

- Clonidine, pentoxifylline, and mexiletine should probably not be considered for the treatment of PDPN (Class Ia, recommendation A [see Supplementary material]).

- The Lidoderm patch may be considered for the treatment of PDPN (Class IIa, recommendation B [see Supplementary material]).

- There is insufficient evidence to support or refute the usefulness of vitamins and $\alpha$-lipoic acid in the treatment of PDPN (Class Ia, recommendation A [see Supplementary material]).

\section{Opioids and NMDA-receptor antagonists}

Tramadol is a centrally acting weak opioid analgesic for treating moderate to severe pain. Tramadol was shown to be better than placebo in a randomized controlled trial ${ }^{86}$ of only 6 weeks' duration, but a subsequent follow-up study suggested that symptomatic relief could be maintained for at least 6 months ${ }^{87}$ Side effects are, however, relatively common, and are similar to other opioid-like drugs. Another spinal cord target for pain relief is the excitatory glutaminergic $N$-methylD-aspartate (NMDA) receptor. Blockade of NMDA receptors is believed to be one mechanism by which dextromethorphan exerts analgesic efficacy. ${ }^{88}$ The NMDA receptors play an important role in central sensitization of neuropathic pain. Their use, however, has not been widespread, in part due to dose-limiting side effects (Class Ia, recommendation A [see Supplementary material] $).{ }^{89}$

Tramadol acts directly via opioid receptors and indirectly via monoaminergic receptor systems. Because the development of tolerance and dependence during long-term tramadol treatment is uncommon and its abuse liability appears to be low, it is an alternative to strong opioids in neuropathic pain. ${ }^{86}$ One conceivable mechanism for the favorable effect of tramadol could be a hyperpolarization of postsynaptic neurons via postsynaptic opioid receptors. Alternatively, the reduction in central hyperexcitability by tramadol could be due to a monoaminergic or a combined opioid and monoaminergic effect.

Severe and refractory pain may require administration of strong opioids such as oxycodone. Although there is little data available on combination treatment, combinations of different substance classes have to be used in patients with pain resistant to monotherapy. Several add-on trials have demonstrated significant pain relief and improvement in QOL following treatment with controlled-release oxycodone, a pure $\mu$-agonist, in patients with painful DSPN whose pain was not adequately controlled on standard treatment with antidepressants and anticonvulsants. ${ }^{90,91}$ As expected, adverse events were frequent and typical of opioid-related side effects. A crossover study examined the maximum tolerable dose of a combination treatment of gabapentin and morphine compared to monotherapy of each drug. The maximum tolerable dose was significantly lower, and efficacy was better during combination therapy than with monotherapy, suggesting an additive interaction between the two drugs. ${ }^{91}$ The results of these studies suggest that opioids should be included among the therapeutic options for painful DSPN, provided that careful selection of patients unresponsive to standard treatments, regular monitoring, appropriate dose titration, and management of possible opioid-specific problems (analgesic misuse or addiction, tolerance, opioid-induced hyperalgesia) are ensured. Recent recommendations have emphasized the need for clinical skills in risk assessment and management as a prerequisite to safe and effective opioid prescribing. ${ }^{69}$ Treatment of painful DSPN with opioid agonists should generally be reserved for patients who have failed to respond to or cannot tolerate the first-line medications.

Tapentadol is a novel centrally active analgesic with a dual mode of action: $\mu$-opioid receptor agonist and norepinephrine-reuptake inhibitor. The efficacy and tolerability of tapentadol extended release (ER) were evaluated using pooled data from two randomized-withdrawal, placebo-controlled, phase III trials of similar design in patients with moderate to severe PDPN. Patients with at least a 1-point reduction in pain intensity at the end of a 3-week open-label titration phase were randomized to receive placebo or tapentadol ER (optimal fixed dose) over 12 weeks. Mean (standard deviation [SD]) pain intensity for the overall population $(n=1034)$ was $7.29(1.38)$ at the start of the open-label titration phase and decreased to $4.15(2.10)$ at the end of titration. With placebo $(n=343)$ and tapentadol ER $(n=360)$, respectively, mean (SD) Pain Intensity Scores were 3.48 (2.02) and 3.67 (1.85) at the start of the double-blind maintenance phase and 4.76 (2.52) and 3.77 (2.19) at week 12. Mean (SD) changes from the start to week 12 were 1.28 (2.41) and 0.08 (1.87), indicating that pain intensity worsened with placebo but was relatively unchanged with tapentadol ER. The least-squares mean difference for the change from start to week 12 for tapentadol ER versus placebo was -1.14 (95\% CI -1.435 to $-0.838, P<0.001$ ). From pretitration (baseline open-label) to the last week of double-blind treatment, $29 \%$ of patients in the placebo group (141/495) and $40 \%$ of patients in the tapentadol group (207/526) had at least a 50\% improvement 
in pain intensity, giving an NNT of 9.2. Adverse events led to treatment discontinuation for $16.3 \%$ (169/1040) of patients during open-label titration, $8.2 \%$ (28/343) of patients receiving placebo, and $14.2 \%(51 / 360)$ of those receiving tapentadol ER during the double-blind maintenance phase. Results of this pooled analysis support those of the individual studies and indicate that tapentadol ER was effective and well tolerated for managing moderate to severe, chronic, painful DPN. ${ }^{92-94}$ Tapentadol has recently been approved by the FDA for the treatment of PDPN.

The AAN recommendations are: ${ }^{15}$

- Dextromethorphan, morphine sulfate, tramadol, and oxycodone should be considered.

- For the treatment of PDPN (level B), data are insufficient to recommend one agent over the other.

For the Toronto Consensus Panel on Diabetic Neuropathy recommendations, please refer to Table $5 .^{72}$ Of note is that the tapentadol publications postdated the AAN and Toronto Consensus Panel recommendations.

\section{Antidepressants}

Antidepressants are now emerging as the first line of agents in the treatment of chronic neuropathic pain. ${ }^{66}$ Clinical trials have focused on interrupting pain transmission by utilizing antidepressant drugs that inhibit the reuptake of norepinephrine or serotonin. This central action accentuates the effects of these neurotransmitters in activation of endogenous pain-inhibitory systems in the brain that modulate pain-transmission cells in the spinal cord. ${ }^{95}$ Putative mechanisms of pain relief by antidepressants include the inhibition of norepinephrine and/or serotonin reuptake at synapses of central descending pain-control systems and the antagonism of NMDA receptors that mediate hyperalgesia and allodynia.

\section{Tricyclic antidepressants}

Imipramine, amitriptyline, and clomipramine induce a balanced reuptake inhibition of both norepinephrine and serotonin, while desipramine is a relatively selective norepinephrine inhibitor. The NNT (CI) for $\geq 50 \%$ pain relief by tricyclic antidepressants (TCAs) in painful neuropathies is 2.1 (1.9-2.6). The number needed to harm in patients with neuropathic pain for one dropout of the study due to adverse events is 16 (11-26). ${ }^{67}$ The starting dose of amitriptyline should be $25 \mathrm{mg}$ (10 mg in frail patients), taken as a single nighttime dose 1 hour before sleep. It should be increased by $25 \mathrm{mg}$ at weekly intervals until pain relief is achieved or adverse events occur. The maximum dose is usually $150 \mathrm{mg}$ per day.
The most frequent adverse events of TCAs include tiredness and dry mouth. TCAs should be used with caution in elderly patients, patients with glaucoma, orthostatic hypotension and diabetic uropathy; and are contraindicated in patients with unstable angina, recent ( $<6$ months) myocardial infarction, heart failure, history of ventricular arrhythmias, significant conduction system disease, and long QT syndrome. Their use is limited by relatively high rates of adverse events and several contraindications. Thus, there is a continuing need for agents that exert efficacy equal to or greater than that achieved with TCAs and that have a more favorable side-effect profile (Class Ia, recommendation A [see Supplementary material]]).

\section{Selective serotonin reuptake inhibitors}

Because of the relative high rates of adverse effects and several contraindications of TCAs, it has been reasoned whether patients who do not tolerate them due to adverse events could alternatively be treated with selective serotonin reuptake inhibitors (SSRIs). SSRIs specifically inhibit presynaptic reuptake of serotonin but not norepinephrine, and unlike the tricyclics they lack the postsynaptic receptor-blocking effects and quinidine-like membrane stabilization. However, only weak effects on neuropathic pain were observed after treatment with fluoxetine, paroxetine, citalopram, and escitalopram. The NNT (CI) for $\geq 50 \%$ pain relief by SSRIs in painful neuropathies is 6.8 (3.9-27). ${ }^{67}$ Because of these limited efficacy data, SSRIs have not been licensed for the treatment of neuropathic pain (Class IIb, recommendation B [see Supplementary material]).

\section{Serotonin-noradrenaline reuptake inhibitors}

Because SSRIs have been found to be less effective than TCAs, recent interest has focused on antidepressants with dual selective inhibition of serotonin and noradrenaline, such as duloxetine and venlafaxine. Serotonin-noradrenaline reuptake inhibitors (SNRIs) relieve pain by increasing the synaptic availability of 5-hydroxytryptamine and noradrenaline in the descending pathways that are inhibitory to pain impulses. A further advantage of duloxetine is that it has antidepressant effects in addition to analgesic effects in diabetic neuropathy.

The efficacy and safety of duloxetine were evaluated in three controlled studies using doses of 60 and $120 \mathrm{mg}$ /day over 12 weeks. ${ }^{96}$ In all three studies, the average 24-hour pain intensity was significantly reduced with both doses compared to placebo treatment, the difference between active and placebo achieving statistical significance after 1 week. The pooled data from the three trials confirmed that 
efficacy was maintained throughout the treatment period of 12 weeks and that approximately $50 \%$ of patients had achieved at least $50 \%$ pain reduction. The response rates, defined as $\geq 50 \%$ pain reduction, were $48.2 \%$ (120 mg/day), $47.2 \%$ (60 mg/day), and 27.9\% (placebo), giving an NNT of 4.9 (95\% CI 3.6-7.6) for $120 \mathrm{mg} /$ day and 5.3 (3.8-8.3) for $60 \mathrm{mg} /$ day. Pain severity, but not variables related to diabetes or neuropathy, predicts the effects of duloxetine in diabetic peripheral neuropathic pain. Patients with higher pain intensity tend to respond better than those with lower pain levels. ${ }^{97}$ Duloxetine reduced interference with general activity and improved SF-36 and EQ-5D scores in two of the three clinical trials. ${ }^{98,99}$ The most frequent side effects of duloxetine (60/120 mg/day) include nausea (16.7\%/27.4\%), somnolence $(20.2 \% / 28.3 \%)$, dizziness $(9.6 \% / 23 \%)$, constipation $(14.9 \% / 10.6 \%)$, dry mouth $(7.1 \% / 15 \%)$, and reduced appetite $(2.6 \% / 12.4 \%)$. These adverse events are usually mild to moderate and transient. To minimize them, the starting dose should be $30 \mathrm{mg} /$ day for 4-5 days. Nonetheless, physicians must be aware about the possibility of orthostatic hypotension during the first week of treatment on the $30 \mathrm{mg}$ dose. In contrast to TCAs and some anticonvulsants, duloxetine does not cause weight gain, but a small increase in fasting blood glucose may occur. ${ }^{100}$

Venlafaxine is another SNRI that has mixed action on catecholamine uptake. At lower doses, it inhibits serotonin uptake, and at higher doses it inhibits norepinephrine uptake. ${ }^{101}$ The ER version of venlafaxine was found to be superior to placebo in diabetic neuropathic pain in nondepressed patients at doses of 150-225 mg daily, and when added to gabapentin there was improved pain, mood, and QOL. ${ }^{102}$ In a 6-week trial comprising 244 patients, the analgesic response rates were $56 \%, 39 \%$, and $34 \%$ in patients given 150-225 mg venlafaxine, $75 \mathrm{mg}$ venlafaxine, and placebo, respectively. Because patients with depression were excluded, the effect of venlafaxine (150-225 mg) was attributed to an analgesic rather than antidepressant effect. The most common adverse events were tiredness and nausea. ${ }^{103}$ Duloxetine, but not venlafaxine, has been licensed in the US for the treatment of painful diabetic neuropathy (Class Ia, recommendation A [see Supplementary material]).

The AAN recommendations are: ${ }^{15}$

- Amitriptyline, venlafaxine, and duloxetine should be considered for the treatment of PDPN (level B). Data are insufficient to recommend one of these agents over the others.

- Venlafaxine may be added to gabapentin for a better response (level $\mathrm{C}$ ).
- There is insufficient evidence to support or refute the use of desipramine, imipramine, fluoxetine, or the combination of nortriptyline and fluphenazine in the treatment of PDPN (level U).

For the Toronto Consensus Panel on Diabetic Neuropathy recommendations, please refer to Table $5 .^{72}$

\section{Antiepileptic drugs}

Antiepileptic drugs (AEDs) have a long history of effectiveness in the treatment of neuropathic pain. ${ }^{104}$ Principal mechanisms of action include sodium-channel blockade (felbamate, lamotrigine, oxcarbazepine, topiramate, zonisamide), potentiation of GABA activity (tiagabine, topiramate), calcium-channel blockade (felbamate, lamotrigine, topiramate, zonisamide), antagonism of glutamate at NMDA receptors (felbamate) or $\alpha$-amino-3-hydroxy-5-methyl4-isoxazole propionic acid (felbamate, topiramate), and mechanisms of action yet to be fully determined (gabapentin, pregabalin, levetiracetam). ${ }^{105}$ An understanding of the mechanisms of action of the various drugs leads to the concept of "rational polytherapy," where drugs with complementary mechanisms of action can be combined for synergistic effect. For example, one might choose a sodium-channel blocker such as lamotrigine to be used with a glutamate antagonist such as felbamate. Furthermore, a single drug may possess multiple mechanisms of action, perhaps increasing its likelihood of success (eg, topiramate). If pain is divided according to its derivation from different nerve-fiber types (eg, A $\delta$ vs C fiber), spinal cord or cortical, then different types of pain should respond to different therapies.

In addition to providing efficacy against epilepsy, these new AEDs may also be effective in neuropathic pain. For example, spontaneous activity in regenerating smallcaliber primary afferent nerve fibers may be quelled by sodium-channel blockade, and hyperexcitability in dorsal horn spinal neurons may be decreased by the inhibition of glutamate release: two mechanisms of action possessed by lamotrigine. ${ }^{106,107}$ Clinical trials, however, have not been salutary. ${ }^{13}$ In addition, the "wind-up" phenomenon caused by nerve injury and the kindling that occurs in hippocampal neurons in patients with mesial temporal sclerosis both enlist activation of NMDA receptors, ${ }^{108,109}$ which can be antagonized by felbamate. ${ }^{105}$ The evidence supporting the use of AEDs for the treatment of PDPN continues to evolve. ${ }^{101}$ Patients who have failed to respond to one AED may respond to another or to two or more drugs in combination (Class Ia, recommendation A [ $\underline{\text { see }}$ Supplementary material]). ${ }^{110}$ 


\section{Calcium-channel modulators (gabapentin and pregabalin)}

Five types of voltage-gated calcium channels have been identified, and the L- and N-types of channels have a role to play in the neuromodulation of sensory neurons of the spinal cord. Gabapentin and pregabalin are medications that bind at the alpha 2 delta subunits of the channels. Unlike traditional calcium-channel antagonists, they do not block calcium channels but modulate their activity and sites of expression. The exact mechanism of action of this group of agents on neuromodulation has yet to be clearly defined (Class IIb, recommendation B [see Supplementary material]).

Gabapentin is an anticonvulsant structurally related to GABA, a neurotransmitter that plays a role in pain transmission and modulation. The exact mechanisms of action of this drug in neuropathic pain are not fully elucidated. Among others, they involve an interaction with the L-amino acid transporter system and high affinity binding to the $\alpha 2-\delta$ subunit of voltage-activated calcium channels. In an 8-week multicenter dose-escalation trial involving 165 diabetic patients with painful neuropathy, $60 \%$ of the patients on gabapentin ( $3600 \mathrm{mg} /$ day achieved in $67 \%$ ) had at least moderate pain relief compared to $33 \%$ on placebo. Dizziness and somnolence were the most frequent adverse events, occurring in about $23 \%$ of the patients in each group. ${ }^{111}$ The NNT (CI) for $\geq 50 \%$ pain relief by gabapentin in painful neuropathies is $6.4(4.3-12)$. Due to this relatively high NNT and publication bias towards unpublished negative trials, ${ }^{112}$ the overall level of evidence in favor of gabapentin in painful DSPN is weak. Gabapentin has the additional benefit of improving sleep, ${ }^{111}$ which is often compromised in patients with chronic pain. ${ }^{110}$ Over the long term, it is known to produce weight gain, which may complicate diabetes management. ${ }^{113}$ Combination therapy has been examined using gabapentin and morphine, indicating slight superiority of the combination (Class Ia, recommendation B [see Supplementary material]). ${ }^{91}$

Pregabalin is a more specific $\alpha 2-\delta$ ligand with a sixfoldhigher binding affinity than gabapentin. Four clinical studies evaluated the efficacy of pregabalin. ${ }^{114-117}$ All studies found that pregabalin relieved pain, but the effect size was small relative to placebo, reducing pain by $11 \%-13 \%$ on the 11-point Likert Scale in three of them. A large dosedependent effect (24\%-50\% reduction in Likert Pain Scores compared to placebo) was observed in the fourth study. ${ }^{117}$ The NNT from these studies for a $50 \%$ reduction in pain was four at $600 \mathrm{mg} /$ day. ${ }^{114-117}$ QOL measures, social functioning, mental health, bodily pain, and vitality improved, and sleep interference decreased, and all changes were significant. The efficacy and safety of pregabalin was further reported in a pooled analysis of seven studies over 5-11 weeks in 1346 diabetic patients with painful neuropathy. ${ }^{118}$ The response rates, defined as $\geq 50 \%$ pain reduction, were $46 \%$ (600 mg/day), $39 \%$ (300 mg/day), 27\% (150 mg/day), and 22\% (placebo), giving NNTs of 4.2, 5.9, and 20.0. Data from this pooled analysis showed an NNT of 4.04 for $600 \mathrm{mg}$ /day and 5.99 for $300 \mathrm{mg} /$ day ${ }^{72}$ The most frequent side effects for $150-600 \mathrm{mg} /$ day were dizziness $(22.0 \%)$, somnolence $(12.1 \%)$, peripheral edema (10.0\%), headache (7.2\%), and weight gain $(5.4 \%) .{ }^{118}$ The evidence supporting a favorable effect in painful diabetic neuropathy is more solid, and dose titration is considerably easier for pregabalin than gabapentin (Class Ia, recommendation A [see Supplementary material]). ${ }^{15}$

Pregabalin improves QOL and lessens sleep interference. As mentioned before, we pooled and analyzed data from eleven randomized, double-blind, placebo-controlled trials of pregabalin for the treatment of DPN (five trials), ${ }^{114-116,119,120}$ PHN (four trials), ${ }^{121-123}$ and DPN/PHN (one trial). ${ }^{117}$ In each trial, patients received either pregabalin or placebo for 8-13 weeks. All studies shared inclusion criteria. In total, 921 patients received placebo and 1735 patients received pregabalin $(150 \mathrm{mg} /$ day $=427 ; 300 \mathrm{mg} /$ day $=496$; $600 \mathrm{mg} /$ day $=672$; flexible dose $=140$ ). Pregabalin treatment resulted in improved patient function/QOL, as assessed by SF-36 scores, compared to placebo. Significant improvements over placebo were evident for the social functioning, role - emotional, mental health, bodily pain, vitality, and

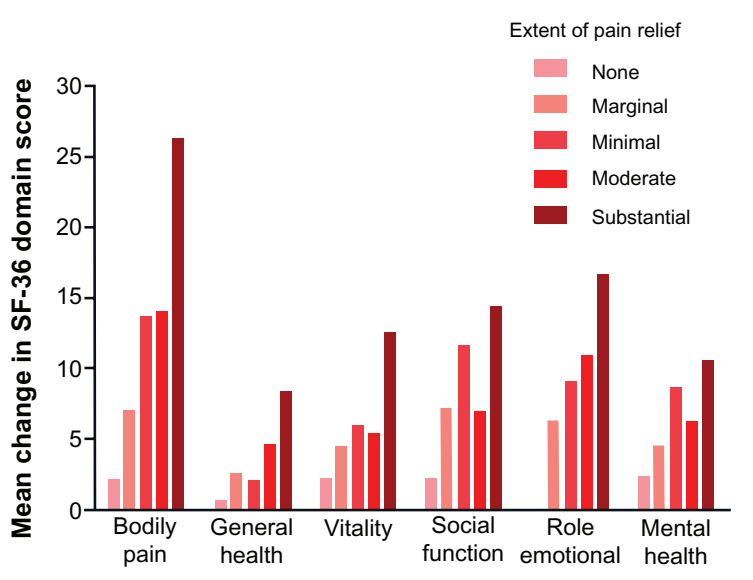

Figure 2 Changes in SF-36 domain scores grouped according to extent of pain relief in patients treated with pregabalin.

Notes: Only SF-36 domains that exhibited significant improvement in response to pregabalin treatment, compared to placebo, are shown. Reprinted from The Journal of Pain. Vinik A, Zlateva G, Cheung R, Murphy K, Emir B, Whalen E. Understanding the impact of pain response on changes in function, quality of life, and sleep interference in patients with painful diabetic peripheral neuropathy and post-herpetic neuralgia treated with pregabalin. 20I0;II:SI7. Copyright 2010 with permission from Elsevier. ${ }^{20}$ 


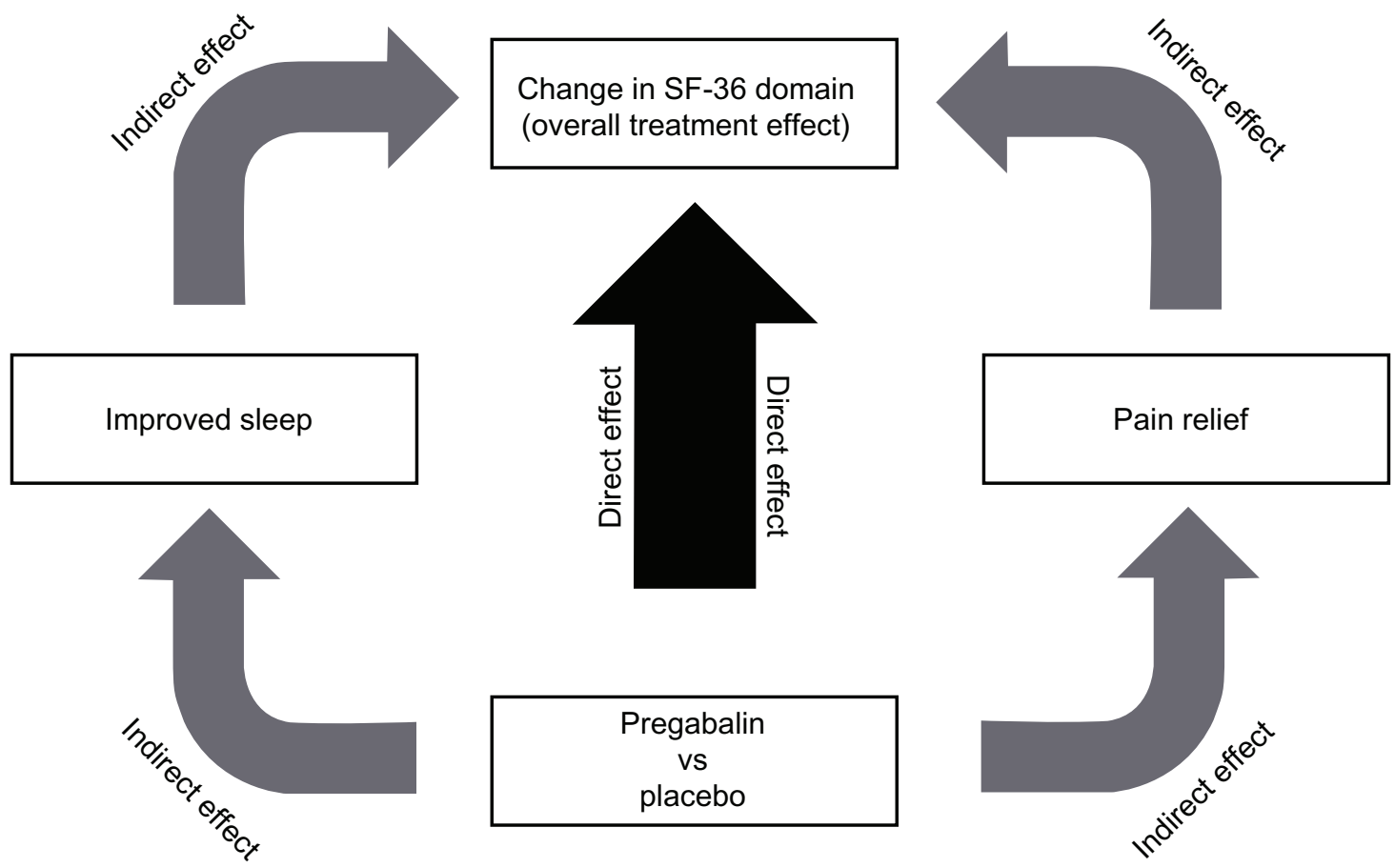

Figure 3 Mediational analysis model, illustrating that the change in SF-36 domain score (overall treatment effect) may be due to a direct effect of pregabalin on that particular SF-36 domain (direct effect) or may be mediated through pregabalin-driven pain relief or improvements in sleep (indirect effects).

Note: Reprinted from The Journal of Pain. Vinik A, Zlateva G, Cheung R, Murphy K, Emir B, Whalen E. Understanding the impact of pain response on changes in function, quality of life, and sleep interference in patients with painful diabetic peripheral neuropathy and post-herpetic neuralgia treated with pregabalin. 20I0; I I:SI7. Copyright 20I0 with permission from Elsevier. ${ }^{20}$

general health domains of the SF-36. ${ }^{20}$ Overall patient status/ quality of life, as assessed by patient global impression of change scores, was also improved in response to pregabalin treatment, with significantly more patients in each pregabalin treatment arm reporting "much improved" or "very much improved" compared to placebo. All pregabalin treatment arms also significantly improved both mean pain and painrelated sleep-interference scores compared to placebo. SF-36 domains exhibited at least a moderate negative linear relationship (correlation coefficient -0.3 ) with pain relief, meaning that SF-36 domain scores increased as mean pain scores decreased (Figure 2). ${ }^{20}$ We further examined to what extent overall changes in SF-36 domain scores (overall treatment effect) were a result of pregabalin-mediated pain relief or improvements in sleep (indirect treatment effect), and to what extent they were due to an independent treatment effect on each specific SF-36 domain (direct treatment effect) using a mediation model (Figure 3). ${ }^{20} \mathrm{~A}$ substantial direct treatment effect ( $18 \%-57 \%$ of the overall treatment effect) of pregabalin was evident for each SF-36 domain analyzed. With respect to the "role - emotional" and mental health domains, a direct treatment effect accounted for a majority $(>50 \%)$ of the overall treatment effect. Changes in the bodily pain domain score were largely due to indirect treatment effects $(81.8 \%$ of the total treatment effect), mostly pain relief $(57.5 \%$ of the total treatment effect). In contrast, while changes to the vitality domain score were also largely due to indirect treatment effects ( $75.1 \%$ of the total treatment effect), changes to this particular domain score were mostly mediated through improvements in sleep ( $43.7 \%$ of the total treatment effect). Overall, our findings demonstrate that in patients with chronic pain due to DPN or PHN, pregabalin-mediated improvements in patient function/QOL are correlated with the extent of pain relief. However, such improvements are not mediated entirely though pain relief, but rather the result of a combination of pregabalin's effects on pain, sleep disturbance, and a direct effect on patient function itself. ${ }^{20}$

\section{Sodium-channel blockers (carbamazepine, oxcarbazepine, lancosamide)}

Voltage-gated sodium channels are crucial determinants of neuronal excitability and signaling. After nerve injury, hyperexcitability and spontaneous firing develop at the site of injury and also in the dorsal root ganglion cell bodies. This hyperexcitability results at least partly from accumulation of sodium channels at the site of injury. ${ }^{124}$ Carbamazepine and oxcarbazepine are most effective against the "lightning" pain produced by such spontaneous neuronal firing. ${ }^{125}$

Although carbamazepine has been widely used for treating neuropathic pain, it cannot be recommended in painful 
diabetic neuropathy due to very limited data. Its successor drug, oxcarbazepine, as well as other sodium-channel blockers, such as valproate, mexiletine, topiramate, and lamotrigine, showed only marginal efficacy and have not been licensed for the treatment of painful diabetic neuropathy.

Lacosamide is a novel anticonvulsant that selectively enhances the slow inactivation of voltage-dependent sodium channels, but in contrast to the aforementioned sodium-channel blockers, it does not influence the fast sodium-channel inactivation. Its second putative mechanism is an interaction with a neuronal cytosolic protein, the collapsin response mediator protein 2, which plays an important role in nerve sprouting and excitotoxicity. Lacosamide has been evaluated in several studies in painful diabetic neuropathy. However, the drug was not approved by the FDA or EMEA for painful diabetic neuropathy in 2008. Further clinical trials may follow in the future (Class $\mathrm{Ib}$, recommendation A [see Supplementary material]).

\section{Topiramate}

Although topiramate failed in three clinical trials, due to the use of the wrong end point, ${ }^{126}$ it has been shown to successfully reduce pain and induce nerve regeneration. ${ }^{32,127}$ Topiramate has the added advantages of causing weight loss and improving the lipoprotein profile, both of which are particularly useful in overweight type 2 diabetic patients. An open-label extension study of topiramate (up to $600 \mathrm{mg}$ /day) in subjects with moderately to severely painful DPN suggested that pain relief was effective, and the drug caused weight loss and improvement in lipid and blood pressure parameters, but $39.5 \%$ of subjects discontinued, most often due to adverse events. ${ }^{72,128}$ Recently, Boyd et al have shown that relief of pain with topiramate treatment associated with improvement in subjective and objective measures of nerve function, intraepidermal nerve-fiber regeneration (Class Ib, recommendation A [see Supplementary material] $),{ }^{129}$ and indices of QOL. ${ }^{130}$

The AAN recommendations are: ${ }^{15}$

- If clinically appropriate, pregabalin should be offered for the treatment of PDPN (level A).

- Gabapentin and sodium valproate should be considered for the treatment of PDPN (level B).

- There is insufficient evidence to support or refute the use of topiramate for the treatment of PDPN (level B).

- Oxcarbazepine, lamotrigine, and lancosamide should probably not be considered for the treatment of PDPN (level B). For the Toronto Consensus Panel on Diabetic Neuropathy recommendations, please refer to Table $5 .^{72}$

Two drugs have been approved for neuropathic pain in the US - pregabalin and duloxetine. A recent meta-analysis in which duloxetine was compared indirectly to pregabalin and gabapentin for the treatment of PDPN concluded that these two drugs have comparable efficacy and tolerability. ${ }^{131}$ Some studies have analyzed health-care costs in patients with PDPN treated with pregabalin, duloxetine, or other usually used drugs. In general, all show similar results, with a good cost-effective profile for both drugs. ${ }^{132-134}$

The response rates to analgesic monotherapy in painful diabetic DSPN are only around 50\%. Therefore, combination pharmacotherapy is required in patients who have only partial response or in whom the drug cannot be further titrated due to intolerable side effects. A recent trial showed that the combination of nortriptyline and gabapentin at the maximum tolerated dose was more effective than either monotherapy, despite a lower maximum tolerable dose as compared with monotherapy. ${ }^{135}$ Appropriate analgesic combinations include antidepressants with anticonvulsants, or each of these with opioids. Some patients may even require a triple combination of these drug classes. The odds ratios for efficacy and withdrawal from medications are given in Table 1 and Figure 1.

On the basis of the clinical trial evidence for the various pharmacological agents (efficacy and safety) for painful DPN, the Toronto Consensus Panel on Diabetic Neuropathy recommended that a TCA, SNRI, or an $\alpha-2-\delta$ agonist (calcium-channel modulator) should be considered for firstline treatments (Table 5). On the basis of trial data, duloxetine would be the preferred SNRI and pregabalin would be the preferred $\alpha-2-\delta$ agonist. If pain is inadequately controlled, depending upon contraindications (Table 5), these first-line agents can be combined, although this is not backed by trial evidence. If pain is still inadequately controlled, opioids such as tramadol and oxycodone might be added in a combination treatment. $^{72}$

During the last decade, it has been recognized that placebo groups in clinical trials also include highly relevant information about the disorder, about study design, and about methodological aspects and developments of research strategies. Indeed, one of the best things one can do with patients in pain is to enter them into a trial; at least $30 \%$ will have a $30 \%$ improvement, even if they only receive placebo. Although clinical trials are typically designed to reveal high effect sizes in the drug group and low effect sizes in the placebo group, for many clinical conditions and treatments the placebo groups can achieve $50 \%-80 \%$ of the positive effects observed in the corresponding drug groups. ${ }^{136}$ Many lessons can be learned by studying the results of placebo groups. Tesfaye et al analyzed data from 262 placebo-administered patients from two identical phase III, randomized, double-blind trials 
of patients with diabetic neuropathy. After 1 year, NIS-LL $(-0.63$ points, $P=0.005)$, vibration detection threshold $(-0.42$ just-noticeable-difference units, $P=0.003)$, and NTSS-6 $(-3.73$ points, $P<0.001)$ improved, whereas some electrophysiology measures and heart rate deep breathing $(-0.78$ beats, $P=0.003)$ worsened compared with baseline values. The authors concluded that in placebo-administered patients with mild symptomatic DPN, there was a progressive improvement in symptoms over 12 months, whereas nerveconduction studies and heart rate deep breathing declined, and clinically significant worsening of DPN would require more than 1 year of observation. ${ }^{137}$ More recently, Häuser et al conducted a systematic review of placebo responses for drug trials in fibromyalgia and PDPN. A total of 72 studies (9827 patients) in fibromyalgia and 70 studies in PDPN (10,297 patients) were included. The authors found that the positive effects in the placebo groups accounted for $45 \%$ of the response in the drug groups in fibromyalgia, and for $62 \%$ in PDPN. The placebo response was higher in PDPN than in fibromyalgia $(P<0.001)$. It was not associated with age, sex, or race, but with year of study initiation, pain baseline, and effect size in active drug groups in both diseases. ${ }^{138}$ Perhaps the lesson to be learned here is that whatever the case, it is important to enter patients with DPN into clinical studies, because even those on placebo do well, possibly due to the increase in vigilance and greater attention to detail for those participating in a study. However, it would be more promising if treatments could address the underlying disorder. It seems that every drug dies 1000 deaths en route to the marketplace, and DPN drugs have fared no better. Perhaps now that we have come to recognize the need for developing therapies that address the most influential factors contributing to nerve dysfunction, we will be able to make progress.

\section{Natural products}

Metanx is a product containing L-methylfolate, pyridoxal 5 '-phosphate, and methylcobalamin for management of endothelial dysfunction. Metanx ingredients counteract endothelial nitric oxide synthase uncoupling and oxidative stress in vascular endothelium and peripheral nerves. Obrosova and Shevalye conducted a 4-week, placebocontrolled study to evaluate the effects of metanx on DPN in Zucker diabetic fatty rats. Compared to controls, metanx-treated groups showed a significant improvement in sensory NCV and thermal and mechanical hypoalgesia, in the absence of any reduction on hyperglycemia. Metanx also increased intraepidermal nerve-fiber density in the rats. ${ }^{139} \mathrm{~A}$ 24-week placebo-controlled trial on the effects of metanx on patients with established diabetic neuropathy was presented at the AACE annual meeting in 2011. The primary end point of the study was vibration perception threshold, which failed to achieve significance. However, NTSS-6, which includes numbness, tingling, aching, burning, lancinating pain, and allodynia, improved significantly at week $16(P=0.013$ vs placebo) and week $24(P=0.033)$. Moreover, there were significant improvements in the mental health component of the SF-36, role-emotional, social function, and vitality. This response occurred with $<2 \%$ adverse events, mainly rash and gastrointestinal upset, and was no greater than placebo. ${ }^{140}$

\section{Botulinum toxin}

Botulinum toxin has been tried for trigeminal neuralgia ${ }^{140}$ and has been shown to have long-lasting antinociceptive effects in carpal tunnel syndrome with no electrophysiologic restoration. ${ }^{141}$

\section{Nonpharmacological treatment of painful diabetic neuropathy}

Because there is no entirely satisfactory pharmacotherapy for painful diabetic neuropathy, nonpharmacological treatment options should always be considered. As for pharmacological treatment, considerable efforts must also be made to develop effective nonpharmacological approaches. A recent systematic review assessed the evidence from rigorous clinical trials and meta-analyses of complementary and alternative therapies for treating neuropathic and neuralgic pain. Data on the following complementary and alternative-medicine treatments were identified: acupuncture, electrostimulation, herbal medicine, magnets, dietary supplements, imagery, and spiritual healing. The conclusion was that the evidence is not fully convincing for most complementary and alternative-medicine modalities in relieving neuropathic pain. The evidence can be classified as encouraging and warrants further study for cannabis extract, magnets, carnitine, and electrostimulation (Class III, recommendation $\mathrm{C}$ [see Supplementary material] $).{ }^{142}$

The AAN recommendations are: ${ }^{15}$

- Percutaneous electrical nerve stimulation should be considered for the treatment of PDPN (level C).

- Electromagnetic field treatment, low-intensity laser treatment, and Reiki therapy should probably not be considered for the treatment of PDPN (level C).

- Evidence is insufficient to support or refute the use of amitriptyline plus electrotherapy for treatment of PDPN (level C). ${ }^{142}$

\section{Psychological support}

A psychological component to pain should not be underestimated. Hence, an explanation to the patient that even severe 
pain may remit is highly encouraged, particularly in poorly controlled patients with acute painful neuropathy or in those painful symptoms precipitated by intensive insulin treatment. Thus, the emphatic approach addressing the concerns and anxieties of patients with neuropathic pain is essential for their successful management. ${ }^{143}$

\section{Physical measures}

The temperature of the painful neuropathic foot may be increased due to arteriovenous shunting. Cold-water immersion may reduce shunt flow and relieve pain. Allodynia may be relieved by wearing silk pajamas or the use of a bed cradle. Patients who describe painful symptoms on walking as comparable to walking on pebbles may benefit from the use of comfortable footwear. ${ }^{143}$

\section{Acupuncture}

In a 10-week uncontrolled study on diabetic patients on standard pain therapy, $77 \%$ showed significant pain relief after up to six courses of traditional Chinese acupuncture without any side effects. During a follow-up period of 18-52 weeks, 67\% were able to stop or significantly reduce their medications, and only $24 \%$ required further acupuncture treatment. ${ }^{144}$ Controlled studies using placebo needles should be performed to confirm these findings.

\section{Electrical stimulation}

The physiological principle underlying transcutaneous electrical nerve stimulation (TENS) is that excitation of $\mathrm{A} \beta$ sensory nerve fibers blocks transmission of pain signals to the brain. TENS influences neuronal afferent transmission and conduction velocity, increases the nociceptive flexion reflex threshold, and changes the somatosensory evoked potentials. In a 4-week study of TENS applied to the lower limbs, each for 30 minutes daily, pain relief was noted in $83 \%$ of the patients compared to $38 \%$ of a sham-treated group. In patients who only marginally responded to amitriptyline, pain reduction was significantly greater following TENS given for 12 weeks as compared with sham treatment. Thus, TENS may be used as an adjunctive modality combined with pharmacotherapy to augment pain relief. ${ }^{145}$

TENS therapy is characterized by its electrical parameters, number and location of electrodes, and dosing schedule. Although all the electrical parameters can be manipulated in an attempt to achieve maximal hypoalgesia, currently published evidence suggests that only stimulation-pulse intensity influences the degree of hypoalgesia. ${ }^{146,147} \mathrm{~A}$ recent placebo-controlled study demonstrated a dose-response relationship between intensity and hypoalgesia. ${ }^{148}$ Stimula- tion below the level of sensory perception did not produce hypoalgesia, and the degree of hypoalgesia was correlated with the stimulation intensity. These and other studies show that TENS should be delivered at a "strong but not painful" level. It has also been shown that increasing simulation intensity during treatment improves the degree of hypoalgesia. ${ }^{149}$ This effect is thought to relate to habituation of the sensory afferents to stimulation.

There are hundreds of commercial TENS and TENS-like devices with different characteristics and features. Unlike the relatively straightforward dosing of oral analgesic drugs, TENS devices are intended to be used by patients with neuropathic pain on an ongoing basis. There is some evidence that a barrier to effective use of TENS is the disproportionate amount of effort needed to regularly apply TENS for the amount of pain relief achieved. As currently designed, most commercial devices offer many different stimulation modes and capabilities, but they fail to optimize dosing to therapeutic levels. Recent advances in commercial TENS technology are targeted at painful diabetic neuropathy and utilize inconspicuous wearable designs, automation, and stimulation algorithms that adapt to patient physiology to optimize stimulation intensity.

One randomized controlled study showed a better effect of mid-frequency external muscle stimulation than TENS on neuropathic symptoms after 1 week, but longer-term controlled studies are not available. Frequency-modulated electromagnetic nerve stimulation applied during ten sessions over 3 weeks resulted in a significant pain reduction compared to placebo stimulation. A larger-scale multicenter study is ongoing (Class IIb, recommendation B [see Supplementary material]).

In diabetic painful neuropathy that was unresponsive to drug treatment, electrical spinal cord stimulation with electrodes implanted between T9 and T11 resulted in pain relief $>50 \%$ in eight out of ten patients. In addition, exercise tolerance was significantly improved. Complications of electrical spinal cord stimulation included superficial wound infection in two patients, lead migration requiring reinsertion in two patients, and "late failure" after 4 months in a patient who had initial pain relief. ${ }^{150}$ This invasive treatment option should be reserved for patients who do not respond to drug treatment (Class IIb, recommendation B [see Supplementary material]).

\section{Surgical decompression}

Surgical decompression at the site of anatomic narrowing has been promoted as an alternative treatment for patients with symptomatic DSPN. A systematic review of the literature revealed only class IV studies concerning the utility of this 


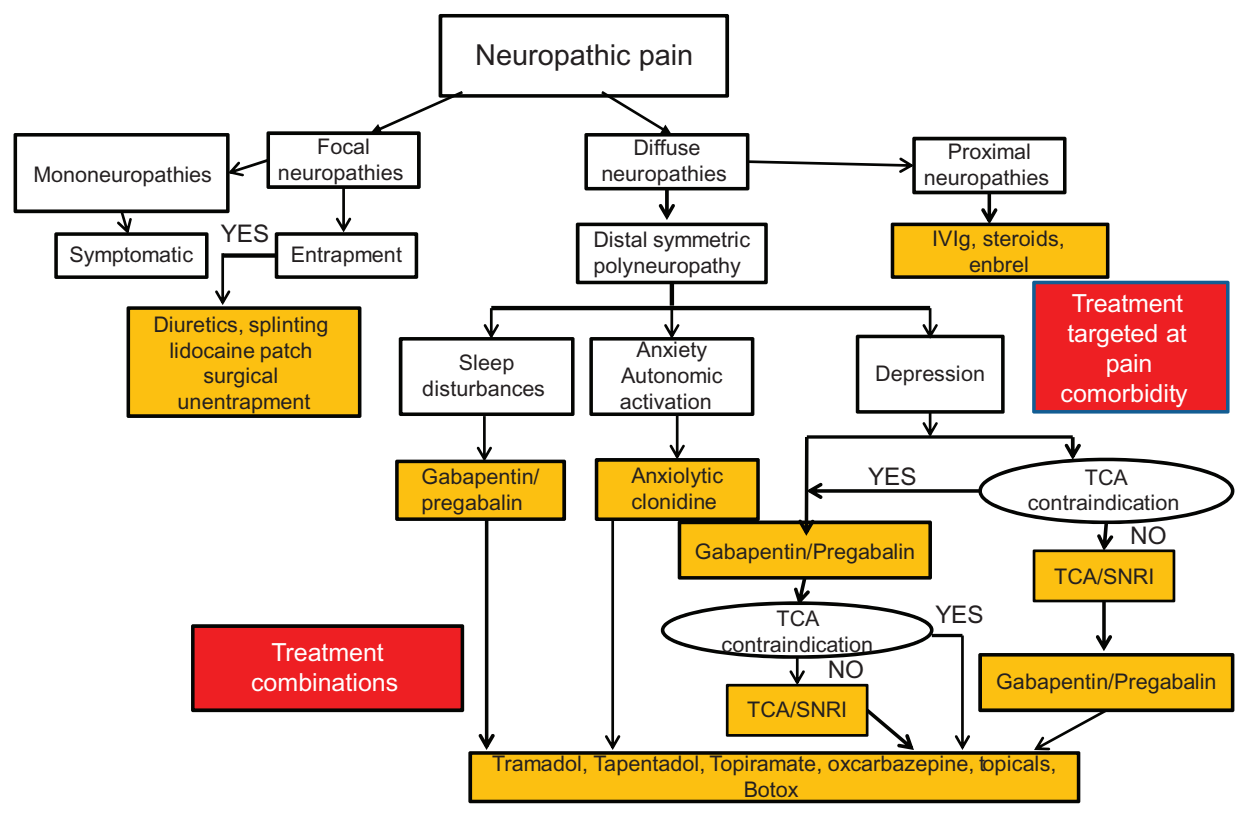

Figure 4 Treatment algorithm: neuropathic pain after exclusion of non-diabetic etiologies and stabilization of glycemic control.

Note: Copyright (C) 2010, The Endocrine Society. Reproduced with permission from Vinik A. The approach to the management of the patient with neuropathic pain. J Clin Endocrinol Metab. 2010;95:4802-4811. ${ }^{70}$

Abbreviations: IVlg, intravenous immunoglobulin; SNRI, serotonin-noradrenaline reuptake inhibitors; TCA, tricyclic antidepressants.

therapeutic approach. Given the current evidence available, this treatment alternative should be considered unproven (Class IV, recommendation C [see Supplementary material] ). Prospective randomized controlled trials with standard definitions and outcome measures are necessary to determine the value of this therapeutic intervention. ${ }^{151,152}$

\section{Guidelines for treatment of painful neuropathy}

Figure 4 (modified from Vinik ${ }^{70}$ ) is an algorithm that we propose for the management of painful neuropathy in diabetes. This presumes that the cause of the pain has been attributed to DPN and that all causes masquerading as DPN have been excluded. The identification of neuropathic pain as being focal or diffuse dictates the initial course of action. Focal neuropathic pain is best treated with diuretics to reduce edema in the canal, splinting, and surgery to release entrapment. Diffuse neuropathies are treated with medical therapy, and in a majority of cases need multidrug therapy. Essential to the evaluation is the identification of the comorbidities and the choice of drugs that can serve dual actions, eg, pregabalin improves sleep and pain both by direct and indirect pathways, whereas duloxetine may reduce depression and anxiety that accompany pain. Immune-mediated neuropathies are treated with intravenous immunoglobulin, steroid, or other immunomodulators. When single agents fail, combinations of drugs with different mechanisms of action are in order. Also provided is the evidence-based recommendation of the AAN and the Toronto Consensus Panel, the NNT, the numbers needed to harm, and the likelihood ratios for use of the drugs and for non-adherence.

\section{Conclusion}

Painful neuropathy is an important complication of diabetes. Pathogenesis is multifactorial and requires attention to detailed management if one is to achieve success. Two drugs have been approved for neuropathic pain in the US - pregabalin and duloxetine - but neither of these afford complete relief, even when used in combination. Indeed, a sobering view is that few drugs achieve greater than $30 \%$ reduction in pain in $>50 \%$ of patients, dictating a need to use more than one drug with different mechanisms of action. There is a great need to understand pathogenic mechanisms more fully, particularly the differences in origin of peripheral and central pain. One needs to be aware of the conditions that masquerade as painful neuropathy and the treatment directed towards the underlying disorder, as suggested in the algorithm provided. Neuropathic pain in diabetes is common and is due to a variety of different neuropathies. Mechanisms of pain are being unraveled. Central sensitization in the spinal cord and the central nervous system are revealing pathways and specific receptors that may lead to novel forms of intervention. Comorbidities that accompany pain include depression, anxiety, and sleep disturbances, all of which must be addressed for successful management of pain. Treatment of peripheral neuropathic pain conditions can benefit from further understanding of the impact of pain response on QOL, 
activities of daily living, and sleep. As Winston Churchill said, "We need to go from failure to failure without losing our enthusiasm and ultimately we will succeed."

Recommendations for future research have been suggested by AAN and the Toronto Consensus Panel and include the following:

- A formalized process for rating pain scales for use in all clinical trials should be developed.

- Clinical trials should be expanded to include effects on QOL and physical function when evaluating efficacy of new interventions for PDPN; the measures should be standardized.

- Future clinical trials should include head-to-head comparisons of different medications and combinations of medications.

- Because PDPN is a chronic disease, trials of longer duration should be done.

- Standard metrics for side effects to qualify effect sizes of interventions need to be developed.

- Cost-effectiveness studies of different treatments should be done.

- Further research is required to find novel and more effective pathogenic treatments for painful DPN.

- Key target areas generating or modulating pain in the brain require further studies in order to develop more effective treatments for PDPN.

- The mechanism of action of electrical stimulation is unknown; a better understanding of its role, mode of application, and other aspects of its use should be studied.

\section{Disclosure}

The authors report no conflicts of interest in this work.

\section{References}

1. Vinik A, Ullal J, Parson HK, Casellini CM. Diabetic neuropathies: clinical manifestations and current treatment options. Nat Clin Pract Endocrinol Metab. 2006;2:269-281.

2. Sadosky A, McDermott AM, Brandenburg NA, Strauss M. A review of the epidemiology of painful diabetic peripheral neuropathy, postherpetic neuralgia, and less commonly studied neuropathic pain conditions. Pain Pract. 2008;8:45-56.

3. Tesfaye S, Boulton AJ, Dyck PJ, et al. Diabetic neuropathies: update on definitions, diagnostic criteria, estimation of severity, and treatments. Diabetes Care. 2010;33:2285-2293.

4. Ziegler D. Painful diabetic neuropathy: treatment and future aspects. Diabetes Metab Res Rev. 2008;24 Suppl 1:S52-S57.

5. Boulton AJ, Malik RA, Arezzo JC, Sosenko JM. Diabetic somatic neuropathies. Diabetes Care. 2004;27:1458-1486.

6. Vinik AI, Ziegler D. Diabetic cardiovascular autonomic neuropathy. Circulation. 2007;115:387-397.

7. Vinik AI, Maser RE, Ziegler D. Neuropathy: the crystal ball for cardiovascular disease? Diabetes Care. 2010;33:1688-1690.

8. Vinik A, Maser R, Ziegler D. Autonomic imbalance: prophet of doom or scope for hope? Diabet Med. 2011;28:643-651.

9. Mantyselka P, Ahonen R, Kumpusalo E, Takala J. Variability in prescribing for musculoskeletal pain in Finnish primary health care. Pharm World Sci. 2001;23:232-236.
10. Treede RD, Jensen TS, Campbell JN, et al. Neuropathic pain: redefinition and a grading system for clinical and research purposes. Neurology. 2008;70:1630-1635.

11. Jensen MP, Chodroff MJ, Dworkin RH. The impact of neuropathic pain on health-related quality of life: review and implications. Neurology. 2007;68:1178-1182.

12. Bouhassira D, Lanteri-Minet M, Attal N, Laurent B, Touboul C. Prevalence of chronic pain with neuropathic characteristics in the general population. Pain. 2008;136:380-387.

13. Vinik EJ, Hayes RP, Oglesby A, et al. The development and validation of the Norfolk QOL-DN, a new measure of patients' perception of the effects of diabetes and diabetic neuropathy. Diabetes Technol Ther. 2005;7:497-508.

14. Vinik E, Paulson J, Ford-Molvik S, Vinik A. German-translated Norfolk quality of life (QOL-DN) identifies the same factors as the English version of the tool and discriminates different levels of neuropathy severity. J Diabetes Sci Technol. 2008;2:1075-1086.

15. Bril V, England J, Franklin GM, et al. Evidence-based guideline: treatment of painful diabetic neuropathy: report of the American Academy of Neurology, the American Association of Neuromuscular and Electrodiagnostic Medicine, and the American Academy of Physical Medicine and Rehabilitation. Neurology. 2011;76:1758-1765.

16. Castro MM, Daltro C. Sleep patterns and symptoms of anxiety and depression in patients with chronic pain. Arq Neuropsiquiatr. 2009;67:25-28.

17. Gore M, Brandenburg NA, Dukes E, Hoffman DL, Tai KS, Stacey B. Pain severity in diabetic peripheral neuropathy is associated with patient functioning, symptom levels of anxiety and depression, and sleep. J Pain Symptom Manage. 2005;30:374-385.

18. Boulanger L, Zhao Y, Foster TS, Fraser K, Bledsoe SL, Russell MW. Impact of comorbid depression or anxiety on patterns of treatment and economic outcomes among patients with diabetic peripheral neuropathic pain. Curr Med Res Opin. 2009;25:1763-1773.

19. Gupta A, Silman J, Ray D, et al. The role of psychosocial factors in predicting the onset of chronic widespread pain: results from a prospective population-based study. Rheumatology (Oxford). 2007;46:666-671.

20. Vinik A, Zlateva G, Cheung R, Murphy K, Emir B, Whalen E. Understanding the impact of pain response on changes in function, quality of life, and sleep interference in patients with painful diabetic peripheral neuropathy and post-herpetic neuralgia treated with pregabalin. J Pain. 2010;11:S17.

21. O'Connor AB. Neuropathic pain: quality-of-life impact, costs and cost effectiveness of therapy. Pharmacoeconomics. 2009;27:95-112.

22. Van Acker K, Bouhassira D, De Bacquer D, et al. Prevalence and impact on quality of life of peripheral neuropathy with or without neuropathic pain in type 1 and type 2 diabetic patients attending hospital outpatients clinics. Diabetes Metab. 2009;35(3):206-213.

23. Daousi C, MacFarlane IA, Woodward A, Nurmikko TJ, Bundred PE, Benbow SJ. Chronic painful peripheral neuropathy in an urban community: a controlled comparison of people with and without diabetes. Diabet Med. 2004;21:976-982.

24. Krein SL, Heisler M, Piette JD, Makki F, Kerr EA. The effect of chronic pain on diabetes patients' self-management. Diabetes Care. 2005;28:65-70.

25. Zelman DC, Brandenburg NA, Gore M. Sleep impairment in patients with painful diabetic peripheral neuropathy. Clin J Pain. 2006;22:681-685.

26. Torrance N, Smith BH, Bennett MI, Lee AJ. The epidemiology of chronic pain of predominantly neuropathic origin. Results from a general population survey. J Pain. 2006;7:281-289.

27. Dieleman JP, Kerklaan J, Huygen FJ, Bouma PA, Sturkenboom MC. Incidence rates and treatment of neuropathic pain conditions in the general population. Pain. 2008;137:681-688.

28. Cornblath DR, Vinik A, Feldman E, Freeman R, Boulton AJ. Surgical decompression for diabetic sensorimotor polyneuropathy. Diabetes Care. 2007;30:421-422.

29. Smith AG, Russell J, Feldman EL, et al. Lifestyle intervention for pre-diabetic neuropathy. Diabetes Care. 2006;29:1294-1299. 
30. Ziegler D, Rathmann W, Meisinger C, Dickhaus T, Mielck A. Prevalence and risk factors of neuropathic pain in survivors of myocardial infarction with pre-diabetes and diabetes. The KORA Myocardial Infarction Registry. Eur J Pain. 2009;13:582-587.

31. Ziegler D, Rathmann W, Dickhaus T, Meisinger C, Mielck A. Neuropathic pain in diabetes, prediabetes and normal glucose tolerance: the MONICA/ KORA Augsburg Surveys S2 and S3. Pain Med. 2009;10:393-400.

32. Pittenger G, Mehrabyan A, Simmons K, et al. Small fiber neuropathy is associated with the metabolic syndrome. Metab Syndr Relat Disord. 2005;3:113-121.

33. Tesfaye S, Chaturvedi N, Eaton SE, et al. Vascular risk factors and diabetic neuropathy. $N$ Engl J Med. 2005;352:341-350.

34. Abbott CA, Malik RA, Van Ross ER, Kulkarni J, Boulton AJ. Prevalence and characteristics of painful diabetic neuropathy in a large community-based diabetic population in the UK. Diabetes Care. 2011;34:2220-2224.

35. Boulton AJ, Armstrong WD, Scarpello JH, Ward JD. The natural history of painful diabetic neuropathy - a 4-year study. Postgrad Med J. 1983;59:556-559.

36. Galer BS, Gianas A, Jensen MP. Painful diabetic polyneuropathy: epidemiology, pain description, and quality of life. Diabetes Res Clin Pract. 2000;47:123-128.

37. Young RJ, Ewing DJ, Clarke BF. Chronic and remitting painful diabetic polyneuropathy. Correlations with clinical features and subsequent changes in neurophysiology. Diabetes Care. 1988;11:34-40.

38. Benbow SJ, Chan AW, Bowsher D, MacFarlane IA, Williams G. A prospective study of painful symptoms, small-fibre function and peripheral vascular disease in chronic painful diabetic neuropathy. Diabet Med. 1994;11:17-21.

39. Vinik AI, Strotmeyer ES, Nakave AA, Patel CV. Diabetic neuropathy in older adults. Clin Geriatr Med. 2008;24:407-435, v.

40. De Micheli A. Italian standards for diabetes mellitus 2007: executive summary: Diabete Italia, AMD Associazione Medici Diabetologi, SID Società Italiana di Diabetologia. Acta Diabetol. 2008;45: 107-127.

41. Bennett MI, Attal N, Backonja MM, et al. Using screening tools to identify neuropathic pain. Pain. 2007;127:199-203.

42. Bastyr E, Zhang D, Bril V, MBBQ Study Group. Neuropathy total symptom score-6 questionnaire (NTSS-6) is a valid instrument for assessing the positive symptoms of diabetic peripheral neuropathy (DPN). Diabetes. 2002;51:A199.

43. Scholz J, Mannion RJ, Hord DE, et al. A novel tool for the assessment of pain: validation in low back pain. PLoS Med. 2009;6:e1000047.

44. Spallone V. Painful Diabetic Neuropathy: Approach to diagnosis and treatment of an emergent problem. Me Dia. 2009;9:1-14.

45. Young RJ. Structural functional interactions in the natural history of diabetic polyneuropathy: a key to the understanding of neuropathic pain? Diabet Med. 1993;10 Suppl 2:89S-90S.

46. Feldman EL, Stevens MJ, Thomas PK, Brown MB, Canal N, Greene DA. A practical two-step quantitative clinical and electrophysiological assessment for the diagnosis and staging of diabetic neuropathy. Diabetes Care. 1994;17:1281-1289.

47. Loeser JD, Treede RD. The Kyoto protocol of IASP Basic Pain Terminology. Pain. 2008;137:473-477.

48. Bouhassira D, Attal N, Fermanian J, et al. Development and validation of the Neuropathic Pain Symptom Inventory. Pain. 2004;108:248-257.

49. Bennett MI, Smith BH, Torrance N, Potter J. The S-LANSS score for identifying pain of predominantly neuropathic origin: validation for use in clinical and postal research. J Pain. 2005;6:149-158.

50. Krause S, Backonja M. Development of a neuropathic pain questionnaire. Clin J Pain. 2003;19:306-314.

51. Bouhassira D, Attal N, Alchaar H, et al. Comparison of pain syndromes associated with nervous or somatic lesions and development of a new neuropathic pain diagnostic questionnaire (DN4). Pain. 2005;114:29-36.

52. Freyhagen R, Baron R, Gockel U. Pain Detect: a new screening questionnaire to detect neuropathic components in patients with back pain. Curr Med Res Opin. 2006;22:1911-1920.

53. Portenoy R. Development and testing of a neuropathic pain screening questionnaire: ID Pain. Curr Med Res Opin. 2006;22:1555-1565.
54. Dworkin RH, Turk DC, Revicki DA, et al. Development and initial validation of an expanded and revised version of the Short-Form McGill Pain Questionnaire (SF-MPQ-2). Pain. 2009;144:35-42.

55. Daut RL, Cleeland CS, Flanery RC. Development of the Wisconsin Brief Pain Questionnaire to assess pain in cancer and other diseases. Pain. 1983;17:197-210.

56. Dworkin RH, Turk DC, Wyrwich KW, et al. Interpreting the clinical importance of treatment outcomes in chronic pain clinical trials: IMMPACT recommendations. J Pain. 2008;9:105-121.

57. Cruccu G, Truini A. Tools for assessing neuropathic pain. PLoS Med. 2009;6:e1000045.

58. Lauria G, Hsieh S, Johansson O, et al. European Federation of Neurological Societies/Peripheral Nerve Society guideline on the use of skin biopsy in the diagnosis of small fiber neuropathy. Report of a joint task force of the European Federation of Neurological Societies and the Peripheral Nerve Society. Eur J Neurol. 2010;17:903-912.

59. Stephenson DT, Arneric SP. Neuroimaging of pain: advances and future prospects. J Pain. 2008;9:567-579.

60. Chao CC, Hsieh SC, Tseng MT, Chang YC, Hsieh ST. Patterns of contact heat evoked potentials (CHEP) in neuropathy with skin denervation: correlation of CHEP amplitude with intraepidermal nerve fiber density. Clin Neurophysiol. 2008;119:653-661.

61. Atherton DD, Facer P, Roberts KM, et al. Use of the novel Contact Heat Evoked Potential Stimulator (CHEPS) for the assessment of small fibre neuropathy: correlations with skin flare responses and intra-epidermal nerve fibre counts. BMC Neurol. 2007;7:21.

62. Casanova-Molla J, Grau-Junyent JM, Morales M, Valls-Sole J. On the relationship between nociceptive evoked potentials and intraepidermal nerve fiber density in painful sensory polyneuropathies. Pain. 2011;152:410-418.

63. Chao CC, Tseng MT, Lin YJ, et al. Pathophysiology of neuropathic pain in type 2 diabetes: skin denervation and contact heat-evoked potentials. Diabetes Care. 2010;33:2654-2659.

64. Wong MC, Chung JW. Feasibility of contact heat evoked potentials for detection of diabetic neuropathy. Muscle Nerve. 2011;44:902-906.

65. Casellini CM, Vinik AI. Clinical manifestations and current treatment options for diabetic neuropathies. Endocr Pract. 2007;13:550-566.

66. Finnerup NB, Otto M, McQuay HJ, Jensen TS, Sindrup SH. Algorithm for neuropathic pain treatment: an evidence based proposal. Pain. 2005;118:289-305.

67. Finnerup NB, Sindrup SH, Jensen TS. The evidence for pharmacological treatment of neuropathic pain. Pain. 2010;150:573-581.

68. Dworkin RH, O'Connor AB, Backonja M, et al. Pharmacologic management of neuropathic pain: evidence-based recommendations. Pain. 2007;132:237-251.

69. Dworkin RH, O'Connor AB, Audette J, et al. Recommendations for the pharmacological management of neuropathic pain: an overview and literature update. Mayo Clin Proc. 2010;85:S3-S14.

70. Vinik A. The approach to the management of the patient with neuropathic pain. J Clin Endocrinol Metab. 2010;95:4802-4811.

71. Edelsberg J, Oster G. Summary measures of number needed to treat: how much clinical guidance do they provide in neuropathic pain? Eur J Pain. 2009;13:11-16.

72. Tesfaye S, Vileikyte L, Rayman G, et al. Painful diabetic peripheral neuropathy: consensus recommendations on diagnosis, assessment and management. Diabetes Metab Res Rev. 2011;27:629-638.

73. Said G, Bigo A, Ameri A, et al. Uncommon early-onset neuropathy in diabetic patients. J Neurol. 1998;245:61-68.

74. Dogrul A, Uzbay IT. Topical clonidine antinociception. Pain. 2004;111:385-391.

75. Ziegler D, Nowak H, Kempler P, Vargha P, Low PA. Treatment of symptomatic diabetic polyneuropathy with the antioxidant alpha-lipoic acid: a meta-analysis. Diabet Med. 2004;21:114-121.

76. Ziegler D, Ametov A, Barinov A, et al. Oral treatment with alpha-lipoic acid improves symptomatic diabetic polyneuropathy: the SYDNEY 2 trial. Diabetes Care. 2006;29:2365-2370.

77. Ziegler D, Low PA, Boulton AJM. Antioxidant treatment with alphalipoic acid in diabetic polyneuropathy: a 4-year randomized double-blind trial (NATHAN 1). Diabetologia. 2011;50:S63. 
78. Ziegler D, Low PA, Litchy WJ, et al. Efficacy and safety of antioxidant treatment with alpha-lipoic acid over 4 years in diabetic polyneuropathy: the NATHAN 1 trial. Diabetes Care. 2011;34:2054-2060.

79. Ziegler D. Thioctic acid for patients with symptomatic diabetic polyneuropathy: a critical review. Treat Endocrinol. 2004;3:173-189.

80. Rains C, Bryson HM. Topical capsaicin. A review of its pharmacological properties and therapeutic potential in post-herpetic neuralgia, diabetic neuropathy and osteoarthritis. Drugs Aging. 1995;7:317-328.

81. Derry S, Lloyd R, Moore RA, McQuay HJ. Topical capsaicin for chronic neuropathic pain in adults. Cochrane Database Syst Rev. 2009;4:CD007393.

82. Mason L, Moore RA, Derry S, Edwards JE, McQuay HJ. Systematic review of topical capsaicin for the treatment of chronic pain. BMJ. 2004;328:991.

83. Backonja M, Wallace MS, Blonsky ER, et al. NGX-4010, a highconcentration capsaicin patch, for the treatment of postherpetic neuralgia: a randomised, double-blind study. Lancet Neurol. 2008;7:1106-1112.

84. Baron R, Mayoral V, Leijon G, Binder A, Steigerwald I, Serpell M. Efficacy and safety of combination therapy with 5\% lidocaine medicated plaster and pregabalin in post-herpetic neuralgia and diabetic polyneuropathy. Curr Med Res Opin. 2009;25:1677-1687.

85. Jarvis B, Coukell AJ. Mexiletine. A review of its therapeutic use in painful diabetic neuropathy. Drugs. 1998;56:691-707.

86. Harati Y, Gooch C, Swenson M, et al. Double-blind randomized trial of tramadol for the treatment of the pain of diabetic neuropathy. Neurology. 1998;50:1842-1846.

87. Harati Y, Gooch C, Swenson M, et al. Maintenance of the long-term effectiveness of tramadol in treatment of the pain of diabetic neuropathy. J Diabetes Complications. 2000;14:65-70.

88. Nelson KA, Park KM, Robinovitz E, Tsigos C, Max MB. High-dose oral dextromethorphan versus placebo in painful diabetic neuropathy and postherpetic neuralgia. Neurology. 1997;48:1212-1218.

89. Sang CN. NMDA-receptor antagonists in neuropathic pain: experimental methods to clinical trials. J Pain Symptom Manage. 2000;19:S21-S25.

90. Watson CP, Moulin D, Watt-Watson J, Gordon A, Eisenhoffer J. Controlled-release oxycodone relieves neuropathic pain: a randomized controlled trial in painful diabetic neuropathy. Pain. 2003; 105:71-78.

91. Gilron I, Bailey JM, Tu D, Holden RR, Weaver DF, Houlden RL. Morphine, gabapentin, or their combination for neuropathic pain. N Engl J Med. 2005;352:1324-1334.

92. Schwartz S, Etropolski M, Shapiro DY, et al. Safety and efficacy of tapentadol ER in patients with painful diabetic peripheral neuropathy: results of a randomized-withdrawal, placebo-controlled trial. Curr Med Res Opin. 2011;27:151-162.

93. Vinik A, Shapiro DY, Karcher K, Lange B, Rauschkolb C, Etropolski M. Patient global impression of change (PGIC) and brief pain inventoryshort form (BPI-SF) assessments with tapentadol extended release (ER) for painful diabetic peripheral neuropathy (DPN). 72nd American Diabetes Association 72nd Scientific Sessions; June 8-12, 2012; Philadelphia, PA.

94. Schwartz S, Etropolski MS, Shapiro DY, et al. A pooled analysis evaluating efficacy and tolerability of tapentadol er for chronic, painful diabetic peripheral neuropathy (DPN). 72nd American Diabetes Association 72nd Scientific Sessions; June 8-12, 2012; Philadelphia, PA.

95. Max M, Lynch S, Muir J. Effects of desipramine, amitryptiline and fluoxetine on pain in diabetic neuropathy. $N \mathrm{Engl} \mathrm{J} \mathrm{Med}$ 1992;326:1250-1256.

96. Kajdasz DK, Iyengar S, Desaiah D, et al. Duloxetine for the management of diabetic peripheral neuropathic pain: evidence-based findings from post hoc analysis of three multicenter, randomized, doubleblind, placebo-controlled, parallel-group studies. Clin Ther. 2007 29 Suppl:2536-2546.

97. Ziegler D, Pritchett YL, Wang F, et al. Impact of disease characteristics on the efficacy of duloxetine in diabetic peripheral neuropathic pain. Diabetes Care. 2007;30:664-669.
98. Goldstein DJ, Lu Y, Detke MJ, Lee TC, Iyengar S. Duloxetine vs placebo in patients with painful diabetic neuropathy. Pain. 2005;116: 109-118.

99. Wernicke JF, Pritchett YL, D’Souza DN, et al. A randomized controlled trial of duloxetine in diabetic peripheral neuropathic pain. Neurology. 2006;67:1411-1420.

100. Hardy T, Sachson R, Shen S, Armbruster M, Boulton AJ. Does treatment with duloxetine for neuropathic pain impact glycemic control? Diabetes Care. 2007;30:21-26.

101. Sansone RA, Sansone LA. Pain, pain, go away: antidepressants and pain management. Psychiatry (Edgmont). 2008;5:16-19.

102. Simpson DA. Gabapentin and venlafaxine for the treatment of painful diabetic neuropathy. J Clin Neuromuscul Dis. 2001;3:53-62.

103. Rowbotham MC, Goli V, Kunz NR, Lei D. Venlafaxine extended release in the treatment of painful diabetic neuropathy: a double-blind, placebo-controlled study. Pain. 2004;110:697-706.

104. Blom S. Trigeminal neuralgia: its treatment with a new anticonvulsant drug (g-32883). Lancet. 1962;21:839-840.

105. LaRoche SM, Helmers SL. The new antiepileptic drugs: scientific review. JAMA. 2004;291:605-614.

106. Eisenberg E, Lurie Y, Braker C, Daoud D, Ishay A. Lamotrigine reduces painful diabetic neuropathy: a randomized, controlled study. Neurology. 2001;57:505-509.

107. Leach MJ, Marden CM, Miller AA. Pharmacological studies on lamotrigine, a novel potential antiepileptic drug: II. Neurochemical studies on the mechanism of action. Epilepsia. 1986;27: 490-497.

108. Coderre TJ, Melzack R. The contribution of excitatory amino acids to central sensitization and persistent nociception after formalin-induced tissue injury. J Neurosci. 1992;12:3665-3670.

109. Backonja MM. Use of anticonvulsants for treatment of neuropathic pain. Neurology. 2002;59:S14-S17.

110. Dworkin RH, Backonja M, Rowbotham MC, et al. Advances in neuropathic pain: diagnosis, mechanisms, and treatment recommendations Arch Neurol. 2003;60:1524-1534.

111. Backonja M, Beydoun A, Edwards KR, et al. Gabapentin for the symptomatic treatment of painful neuropathy in patients with diabetes mellitus: a randomized controlled trial. JAMA. 1998;280:1831-1836.

112. Landefeld CS, Steinman MA. The Neurontin legacy - marketing through misinformation and manipulation. N Engl J Med. 2009;360:103-106.

113. DeToledo JC, Toledo C, DeCerce J, Ramsay RE. Changes in body weight with chronic, high-dose gabapentin therapy. Ther Drug Monit. 1997; 19:394-396.

114. Lesser H, Sharma U, LaMoreaux L, Poole RM. Pregabalin relieves symptoms of painful diabetic neuropathy: a randomized controlled trial. Neurology. 2004;63:2104-2110.

115. RichterRW,Portenoy R, SharmaU,LaMoreauxL, BockbraderH,KnappLE. Relief of painful diabetic peripheral neuropathy with pregabalin: a randomized, placebo-controlled trial. J Pain. 2005;6:253-260.

116. Rosenstock J, Tuchman M, LaMoreaux L, Sharma U. Pregabalin for the treatment of painful diabetic peripheral neuropathy: a double-blind, placebo-controlled trial. Pain. 2004;110:628-638.

117. Freynhagen R, Strojek K, Griesing T, Whalen E, Balkenohl M. Efficacy of pregabalin in neuropathic pain evaluated in a 12-week, randomised, double-blind, multicentre, placebo-controlled trial of flexible- and fixed-dose regimens. Pain. 2005;115:254-263.

118. Freeman R, Durso-Decruz E, Emir B. Efficacy, safety, and tolerability of pregabalin treatment for painful diabetic peripheral neuropathy: findings from seven randomized, controlled trials across a range of doses. Diabetes Care. 2008;31:1448-1454.

119. Tolle T, Freynhagen R, Versavel M, Trostmann U, Young JJP. Pregabalin for relief of neuropathic pain associated with diabetic neuropathy: a randomized, double-blind study. Eur J Pain. 2008;12:203-213.

120. Arezzo JC, Rosenstock J, LaMoreaux L, Pauer L. Efficacy and safety of pregabalin $600 \mathrm{mg} / \mathrm{d}$ for treating painful diabetic peripheral neuropathy: a double-blind placebo-controlled trial. BMC Neurol. 2008;8:33. 
121. Sabatowski R, Galvez R, Cherry DA, et al. Pregabalin reduces pain and improves sleep and mood disturbances in patients with post-herpetic neuralgia: results of a randomised, placebo-controlled clinical trial. Pain. 2004;109:26-35.

122. Dworkin RH, Corbin AE, Young JP Jr, et al. Pregabalin for the treatment of postherpetic neuralgia: a randomized, placebo-controlled trial. Neurology. 2003;60:1274-1283.

123. van Seventer R, Feister HA, Young JP Jr, Stoker M, Versavel M, Rigaudy L. Efficacy and tolerability of twice-daily pregabalin for treating pain and related sleep interference in postherpetic neuralgia: a 13-week, randomized trial. Curr Med Res Opin. 2006;22:375-84.

124. Kalso E. Sodium channel blockers in neuropathic pain. Curr Pharm Des. 2005;11:3005-3011.

125. Dogra S, Beydoun S, Mazzola J, Hopwood M, Wan Y. Oxcarbazepine in painful diabetic neuropathy: a randomized, placebo-controlled study. Eur J Pain. 2005;9:543-554.

126. Vinik AI. Diabetic neuropathies: endpoints in clinical research studies. In: LeRoith D, Vinik AI, editors. Controversies in Treating Diabetes: Clinical and Research Aspects (Contemporary Endocrinology). Totowa, NJ: Humana Press; 2008:135-156.

127. Raskin P, Donofrio PD, Rosenthal NR, et al. Topiramate vs placebo in painful diabetic neuropathy: analgesic and metabolic effects. Neurology. 2004;63:865-873.

128. Donofrio PD, Raskin P, Rosenthal NR, et al. Safety and effectiveness of topiramate for the management of painful diabetic peripheral neuropathy in an open-label extension study. Clin Ther. 2005;27:1420-1431.

129. Boyd A, Barlow P, Pittenger G, Simmons K, Vinik A. Topiramate improves neurovascular function, epidermal nerve fiber morphology, and metabolism in patients with type 2 diabetes mellitus. Diabetes Metab Syndr Obes. 2010;2010:431-437.

130. Boyd A, Casellini C, Vinik E, Vinik A. Quality of life and objective measures of diabetic neuropathy in a prospective placebo-controlled trial of ruboxistaurin and topiramate. J Diabetes Sci Technol. 2011;5:714-722.

131. Quilici S, Chancellor J, Lothgren M, et al. Meta-analysis of duloxetine vs pregabalin and gabapentin in the treatment of diabetic peripheral neuropathic pain. BMC Neurol. 2009;9:6-19.

132. Burke JP, Sanchez RJ, Joshi AV, Cappelleri JC, Kulakodlu M, Halpern R. Health care costs in patients with painful diabetic peripheral neuropathy prescribed pregabalin or duloxetine. Pain Pract. 2012;12:209-218.

133. de Salas-Cansado M, Perez C, Saldana MT, et al. An economic evaluation of pregabalin versus usual care in the management of communitytreated patients with refractory painful diabetic peripheral neuropathy in primary care settings. Prim Care Diabetes. Epub May 15, 2012.

134. Bellows BK, Dahal A, Jiao T, Biskupiak J. A cost-utility analysis of pregabalin versus duloxetine for the treatment of painful diabetic neuropathy. J Pain Palliat Care Pharmacother. 2012;26:153-164.

135. Gilron I, Bailey JM, Tu D, Holden RR, Jackson AC, Houlden RL. Nortriptyline and gabapentin, alone and in combination for neuropathic pain: a double-blind, randomised controlled crossover trial. Lancet. 2009;374:1252-1261.

136. Rief W. Lessons to be learned from placebo groups in clinical trials. Pain. 2011;152:1693-1694.

137. Tesfaye S, Tandan R, Bastyr EJ 3rd, Kles KA, Skljarevski V, Price KL. Factors that impact symptomatic diabetic peripheral neuropathy in placebo-administered patients from two 1-year clinical trials. Diabetes Care. 2007;30:2626-2632.
138. Häuser W, Bartram-Wunn E, Bartram C, Reinecke H, Tolle T. Systematic review: placebo response in drug trials of fibromyalgia syndrome and painful peripheral diabetic neuropathy-magnitude and patient-related predictors. Pain. 2011;152:1709-1717.

139. Obrosova I, Shevalye H. Metanx alleviates diabetes-induced large and small fiber neuropathies and promotes small sensory nerve fiber regeneration. Diabetes. 2011;60:652-P.

140. Fonseca VA, Lavery LA, Thethi TK, et al. A 24-week, double-blind, placebo controlled, multicenter study of Metanx in patients with diabetic peripheral neuropathy. Program and abstracts of the American Association of Clinical Endocrinologists 2011 Annual Meeting; April 13-17, 2011; San Diego, CA. Abstract 212.

141. Piovesan EJ, Teive HG, Kowacs PA, la Coletta MV, Werneck LC, Silberstein SD. An open study of botulinum-A toxin treatment of trigeminal neuralgia. Neurology. 2005;65:1306-1308.

142. Tsai CP, Liu CY, Lin KP, Wang KC. Efficacy of botulinum toxin type $\mathrm{a}$ in the relief of carpal tunnel syndrome: a preliminary experience. Clin Drug Investig. 2006;26:511-515.

143. Pittler MH, Ernst E. Complementary therapies for neuropathic and neuralgic pain: systematic review. Clin J Pain. 2008;24:731-733.

144. Tesfaye S. Painful diabetic neuropathy. Aetiology and nonpharmacological treatment. In: Veves A, editor. Clinical Management of Diabetic Neuropathy. Totowa, NJ: Humana Press; 1998:369-386.

145. Abuaisha BB, Costanzi JB, Boulton AJ. Acupuncture for the treatment of chronic painful peripheral diabetic neuropathy: a long-term study. Diabetes Res Clin Pract. 1998;39:115-121.

146. Kumar D. Diabetic peripheral neuropathy: effectiveness of electrotherapy and amitriptyline for symptomatic relief. Diabetes Care. 1998;21:1322-1325.

147. Johnson MI, Bjordal JM. Transcutaneous electrical nerve stimulation for the management of painful conditions: focus on neuropathic pain. Expert Rev Neurother. 2011;11:735-753.

148. Claydon LS, Chesterton LS, Barlas P, Sim J. Dose-specific effects of transcutaneous electrical nerve stimulation (TENS) on experimental pain: a systematic review. Clin J Pain. 2011;27:635-647.

149. Moran F, Leonard T, Hawthorne S, et al. Hypoalgesia in response to transcutaneous electrical nerve stimulation (TENS) depends on stimulation intensity. J Pain. 2011;12:929-935.

150. Pantaleao MA, Laurino MF, Gallego NL, et al. Adjusting pulse amplitude during transcutaneous electrical nerve stimulation (TENS) application produces greater hypoalgesia. J Pain. 2011;12:581-590.

151. Tesfaye S, Watt J, Benbow SJ, Pang KA, Miles J, MacFarlane IA. Electrical spinal-cord stimulation for painful diabetic peripheral neuropathy. Lancet. 1996;348:1698-1701.

152. Therapeutics and Technology Assessment Subcommittee of the American Academy of Neurology, Chaudhry V, Stevens JC, Kincaid J, So YT. Practice Advisory: utility of surgical decompression for treatment of diabetic neuropathy: report of the Therapeutics and Technology Assessment Subcommittee of the American Academy of Neurology. Neurology. 2006;66:1805-1808.

153. Chaudhry V, Russell J, Belzberg A. Decompressive surgery of lower limbs for symmetrical diabetic peripheral neuropathy. Cochrane Database Syst Rev. 2008;16s:CD006152.

154. Endotext.org [homepage on the internet]. Darmouth: Chapter $31-$ Diabetic Neuropathies; 2012 version [updated September 26, 2012]. Available from: http://www.endotext.org/diabetes/diabetes31/diabetesframe31.htm. Accessed December 12, 2012.

Diabetes, Metabolic Syndrome and Obesity: Targets and Therapy

\section{Publish your work in this journal}

Diabetes, Metabolic Syndrome and Obesity: Targets and Therapy is an international, peer-reviewed open-access journal committed to the rapid publication of the latest laboratory and clinical findings in the fields of diabetes, metabolic syndrome and obesity research. Original research, review, case reports, hypothesis formation, expert opinion and commentaries are all considered for publication. The manuscript management system is completely online and includes a very quick and fair peer-review system, which is all easy to use. Visit http://www.dovepress.com/testimonials.php to read real quotes from published authors. 